This is the peer reviewed version of the following article:

Frascari D, Bacca AEM, Wardenaar T, Oertlé E, Pinelli D, 2019. Continuous flow adsorption of phenolic compounds from olive mill wastewater with resin XAD16N: life cycle assessment, cost-benefit analysis and process optimization. Journal of Chemical Technology \& Biotechnology 94, 1968-1981. DOI: 10.1002/jctb.5980

which has been published in final form at https://doi.org/10.1002/jctb.5980.

This article may be used for non-commercial purposes in accordance with Wiley Terms and Conditions for Use of Self-Archived Versions. 


\title{
Continuous flow adsorption of phenolic compounds from olive mill wastewater with resin XAD16N: life cycle assessment, cost-benefit analysis and process optimization
}

Abbreviated title: Polyphenol adsorption from olive mill wastewater: LCA, cost analysis, optimization

Dario Frascari, ${ }^{\mathrm{a}^{*}}$ Aurora Esther Molina Bacca, ${ }^{\mathrm{a}}$ Tjerk Wardenaar, ${ }^{\mathrm{b}}$ Emmanuel Oertlé, ${ }^{\mathrm{c}}$ Davide Pinelli $^{\mathrm{a}}$

${ }^{a}$ Department of Civil, Chemical, Environmental and Materials Engineering, University of Bologna, Italy

${ }^{b}$ PNO Consultants BV, Rijswijk, The Netherlands

${ }^{c}$ Institute for Ecopreneurship, University of Applied Sciences and Arts Northwestern Switzerland, Muttenz, Switzerland

* Correspondence to: D. Frascari, Department of Civil, Chemical, Environmental and Materials Engineering, University of Bologna, Via Terracini 28, 40131 Bologna, Italy. E-mail: dario.frascari@unibo.it

\begin{abstract}
BACKGROUND: Olive mill wastewaters (OMWs) represent a major environmental concern due to their high organic load and phytotoxic activity. The selective recovery of phenolic compounds (PCs) from OMW is promising, thanks to the antioxidant and antimicrobial properties of PCs. The goal of this work was to perform the life cycle assessment (LCA) and cost-benefit analysis (CBA) of a fullscale process of PC adsorption/desorption on resin Amberlite XAD16N. The industrial process was designed on the basis of laboratory tests aimed at performing a preliminary process optimization.

RESULTS: Adsorption tests were conducted at different velocities in a 1.8-m column packed with XAD16N. The optimal superficial velocity and retention time $(2.78 \mathrm{~m} / \mathrm{h}$ and $0.56 \mathrm{~h})$ allowed the attainment of satisfactory performances in terms of resin operating capacity (0.46), PC adsorption yield (0.92), PC mass fraction in the sorbed product $\left(0.50 \mathrm{~g}\right.$ PC $\left./ \mathrm{g}_{\mathrm{VS}}\right)$ and specific antioxidant activity (3-6 gascorbic acid $/ \mathrm{g}_{\mathrm{PC}}$ ). Six consecutive adsorption/desorption cycles, operated with the same resin load, resulted in stable process performances. The LCA indicated that the environmental impact of the process could be markedly decreased through the addition of an anaerobic digestion step for the production of irrigation-quality water and fertilizers from the dephenolized OMW. The PC market price required for the generation of a positive business case resulted reasonable (1.7-13.5 €/ $\left.\mathrm{kg}_{\mathrm{PC}}\right)$.

CONCLUSION: The results indicate that the proposed PC adsorption/desorption technology, if integrated with an anaerobic digestion step, represents a promising solution for the treatment and valorisation of OMW, a major agro-industrial waste in Mediterranean countries.
\end{abstract}

Keywords: phenolic compounds; antioxidants; adsorption; olive mill wastewater; life cycle assessment; cost-benefit analysis 


\section{INTRODUCTION}

Olive mill wastewaters (OMWs) represent a relevant environmental concern. Their high COD content (20-200 g/L) and the presence of phenolic compounds (PCs; 0.1-18 g/L) cause bad smell, inhibition of seed germination and plant growth ${ }^{1-5}$ and inhibition of the aerobic and anaerobic biodegradation processes commonly used to make OMW suitable for irrigation. ${ }^{6,7}$ On the other hand, OMW contains about $95 \%$ of the PC content of the original olives, as a result of the high solubility of PCs in water. ${ }^{1,8}$ PCs have strong antioxidant, anti-inflammatory and antimicrobial properties, and positive health effects were associated to the consumption of PC-rich foods. ${ }^{1,3,9-14}$

Several processes can be applied to recover PCs from OMW: membrane separation processes, solvent extraction, ultrasound treatment, cloud point extraction. ${ }^{15-21}$ Adsorption and ion exchange were successfully studied and implemented for PC recovery from OMW. ${ }^{15,22-29,30}$ They are characterized by a simple design and operation, low operating costs and ease of resin regeneration. ${ }^{31-}$ ${ }^{33}$ On the other hand, the high concentration of carbohydrates and proteins in OMW can lead to a desorbed product characterized by a low PC content. ${ }^{19,34,35}$ The presence of carbohydrates and amino acids generally determines a decrease in the PC adsorption capacity of both neutral and ion exchange resins, due to competitive adsorption phenomena. ${ }^{34}$ However, Kammere et al. ${ }^{34}$ showed that the presence of different types of sugars boosted the adsorption of caffeic acid on neutral adsorption resins, possibly because the multilayer sorption of caffeic acid on the resin surface could be enhanced in the presence of sugars through hydrogen bridges. The interaction between PC, sugars and proteins has never been included in the studies on the modelling of PC adsorption, to the best of the authors' knowledge. A limited number of studies focused on the continuous-flow adsorption or ion exchange of PC mixtures. ${ }^{22-24,27,34-39}$ Only a few of these studies were based on the use of an actual OMW, ${ }^{22-}$ $24,27,28,38,39$ whereas numerous studies used synthetic PC mixtures or other PC-rich wastewaters or natural sources, such as apples, blueberries, grape marcs and artichokes. ${ }^{33-35,40-42}$ The studies on PC adsorption from PC-rich wastewaters and matrixes never included the life-cycle assessment and cost analysis of the process.

The key design elements for a PC adsorption process are: (i) the selection of a suitable resin; (ii) the choice of an appropriate desorption solvent, (iii) the evaluation of the optimal resin bed height and (iv) the selection of a suitable superficial velocity for the adsorption step. A further key factor generally neglected in previous works is the evaluation of the process stability and performance reproducibility during consecutive adsorption/desorption cycles. Indeed, the presence of residual sorbed compounds after each desorption step and the gradual deposition of suspended solids on the initial portion of the column could lead to a gradual decrease in process performances. Previous works relative to PC adsorption from OMW led to the following choices relative to the above-listed points (i), (ii) and (iii):

i) The PC adsorption performances of several neutral and ion exchange resins (XAD16N, XAD4, Optipore SD-2, FPX66, XAD761, IRA958 OH, XAD7, IRA96; Isolute ENV+) were compared. ${ }^{3,15,22-25}$ Bertin et al., ${ }^{3}$ in a comparison between XAD16N, XAD7, IRA96 and Isolute $\mathrm{ENV}+$, obtained the best performances with Isolute ENV+, but also XAD16N led to satisfactory performances. Zagklis et al. ${ }^{15}$ obtained high PC adsorption yields with XAD16N and XAD4, whereas XAD7 risulted less effective. Frascari et al. ${ }^{24}$ report the best performances with XAD16N and IRA958 OH, whereas Optipore SD-2, FPX66 and XAD761 resulted less suitable. On the basis of these results, XAD16N was selected for this study, even if other resins present similar PC adsorption performances.

ii) Acidified ethanol $(0.5 \% \mathrm{v} / \mathrm{v} \mathrm{HCl} 0.1 \mathrm{~N})$ was identified as an effective solvent for PC desorption from resin XAD16N; ${ }^{3,22-25}$

iii) An increase in resin bed height from 0.5 to $1.8 \mathrm{~m}$ led to a marked improvement in resin operating efficiency; ${ }^{23} 1.8 \mathrm{~m}$ was therefore selected as a suitable resin bed height for a further process optimization in terms of fluid velocity.

This work focused on the development of a life cycle assessment (LCA) and cost-benefit analysis (CBA) of a full-scale process of PC recovery by adsorption. The full-scale plant was designed on the basis of the above-reported choices in terms of adsorption resin (XAD16N), 
desorption solvent (acidified ethanol) and resin bed height $(1.8 \mathrm{~m})$. Specific tests were performed in order to identify a suitable superficial velocity and residence time, and a model of the adsorption step was developed in order to correctly assess the performances obtained at each superficial velocity tested. The specific goals of this work were: i) to carry out an LCA and CBA of the PC recovery process, based on the design of a full-scale plant including not only the adsorption/desorption column but also all the equipment required to produce a PC-rich product; ii) to identify suitable superficial velocities for both the adsorption and the desorption step, to be used for the design of the industrial plant; iii) to develop and validate a model of the adsorption process, iv) to test performance reproducibility during consecutive adsorption/desorption cycles. Thus, in this work the presentation of the experimental tests aimed at identifying the optimal velocities for the adsorption and desorption steps and the model-based evaluation of the performances of such tests are followed by the design, LCA and CBA of the full-scale process.

The main novel elements of this study are: i) the LCA of the PC adsorption process; this aspect has been included so far in a very limited number of studies on PC recovery from different matrixes by solvent extraction and subcritical water extraction, ${ }^{16,43}$ but never on PC recovery by adsorption; ii) the CBA of the PC adsorption process; indeed, a few studies report the economic evaluation of processes of PC recovery by reverse osmosis, combined ultrafiltration / nanofiltration, supercritical fluid extraction and thermal treatment combined to centrifugation, ${ }^{44-47}$ but not by adsorption; iii) the development of an LCA and CBA of the PC recovery process based on the design of a full-scale plant that includes all the equipment required to produce a PC-rich product, in addition to the adsorption/desorption column (OMW filtration unit, rotary dryer with gas boiler for ethanol evaporation, condenser for ethanol recovery, cooling tower, tanks and pumps); conversely, the previous studies on the process LCA and CBA did not include the evaluation of the cost and environmental impact associated to the purchase, operation and decommissioning of the auxiliary equipment required to produce a marketable antioxidant product; iv) the model-based study of the effect of fluid velocity on the performances of the PC adsorption process; and v) the assessment of the process performances during consecutive adsorption / desorption cycles; indeed, this aspect has been partially investigated for a continuous flow process only in one previous study ${ }^{15}$ which evaluated - during 5 consecutive cycles - the composition of the desorbed product, but not the adsorption yield or the resin operating efficiency.

\section{EXPERIMENTAL}

\section{Analytical methods}

The total PC content was determined by means of an HPLC method using a C18 Kinetex $2.6 \mu \mathrm{m}$ 100A Phenomenex column, with gallic acid as external standard $(50 \mathrm{mg} / \mathrm{L})$. In order to allow the comparison between the results of this work and those of previous studies of PC adsorption from OMW, the total PC content of the raw OMW and of the selected desorbed products was measured also according to the conventional colorimetric test developed by Folin and Ciocalteu. ${ }^{48}$ All the PC concentrations reported in this study refer to the HPLC method, unless otherwise indicated. Total solid content was measured by drying the sample overnight at $105^{\circ} \mathrm{C}$ and weighing. Suspended solids were determined by filtration with a $0.45 \mu \mathrm{m}$ ALBET cellulose nitrate membrane filter and weighing. COD was measured spectrophotometrically using the Aqualytic COD Vario Tubes (range: 0-1500

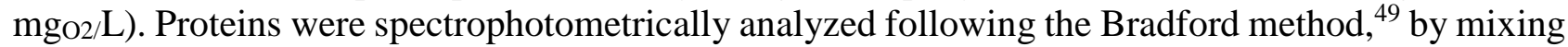
$67 \mu \mathrm{L}$ of sample with $2 \mathrm{~mL}$ of Bradford reagent (VWR International S.r.l). Reducing sugars were analyzed following the dinitrosalicylic acid (DNS) assay by mixing $100 \mu \mathrm{L}$ of sample, $100 \mu \mathrm{L}$ of demineralized water and $100 \mu \mathrm{L}$ of DNS (2-hydroxy-3,5-dinitrobenzoic acid) reagent. ${ }^{50}$ OMW density was measured by means of a $100 \mathrm{~mL}$ ITI Tooling pycnometer. $\mathrm{pH}$ was measured with an EUTECH Instruments pH 2700 Series pH-meter (Thermoscientific, Walthman, Massachusetts). Antioxidant capacity was measured by means of a 2,2'-azino-bis(3-ethylbenzothiazoline-6-sulphonic acid; ABTS) decolorization assay using a Shimazu UV-VIS spectrophotometer (UV-1601). The 
calibration line was obtained using ascorbic acid as standard. More details on the analytical procedures are reported by Frascari et al. ${ }^{22,24}$

\section{OMW, resin and chemicals}

The OMW used in this study was produced by a 3-phase olive mill located near Imperia, in the NorthWest of Italy. The main characteristics of the experimental OMW are reported in Table 1. PCs, proteins and reducing sugars - the 3 classes of organic compounds analysed - represent just $38 \%$ of the total volatile solids. The remaining fraction is typically composed by a complex mixture of compounds such as oligosaccharides, peptines, polyoils and polyalcohols. ${ }^{51,52}$ The PCs $(0.5-1 \mathrm{~g} / \mathrm{L}$, depending on the analytical method), COD $(21 \mathrm{~g} / \mathrm{L})$ and total solids $(13 \mathrm{~g} / \mathrm{L})$ of the tested OMW are quite low, in comparison with the corresponding values typical of OMWs. ${ }^{51,53}$ On the basis of a preliminary identification of the single compounds present in the PC mixture, tyrosol and hydroxytyrosol represent respectively $10 \%$ and $4 \%$ of the total PCs.

All the adsorption tests object of this study were conducted with resin Amberlite XAD16N (DOW Chemicals Europe GmbH, Horgen, Switzerland), a non-ionic styrene-divinylbenzene adsorbent. The main characteristics of this resin are: specific density $1.04 \mathrm{~kg} / \mathrm{L}$, adsorption capacity for medium molecular weight compounds $370 \mathrm{~g} / \mathrm{kg}_{\text {dry resin, }}$, surface area $800 \mathrm{~m}^{2} / \mathrm{g}$, average particle size $0.63 \mathrm{~mm}$ (dry resin), uniformity coefficient 2.0 , maximum reversible swelling $25 \%$. XAD16N was activated as follows: i) resin soaking with acidified ethanol $(0.5 \% \mathrm{HCl} 0.1 \mathrm{~N})$, ii) overnight drying at $105^{\circ} \mathrm{C}$, iii) second resin soaking with acidified ethanol, iv) double washing with demineralized water. Dry resin represented $28 \% \mathrm{w} / \mathrm{w}$ of the resulting activated and hydrated product. Ethanol, the HPLC mobile phase components and gallic were obtained from Sigma Aldrich (Milan, Italy).

\section{OMW pre-treatment}

A 3-step OMW pre-treatment was applied to remove the OMW suspended solids, thus avoiding the adsorption bed clogging: i) OMW centrifugation (4000 rpm, 30 minutes; Thermoscientific SC16R centrifuge, Walthman, Massachusetts), ii) in-line $25 \mu \mathrm{m}$ microfiltration, and iii) in-line $11 \mu \mathrm{m}$ microfiltration (GE Healtcare Life Science Whatman filters). This procedure led to a $99 \%$ suspended solids removal, and to an acceptable PC loss (5-6\%).

\section{Adsorption column packing and fluid-dynamic characterization}

The semi-continuous adsorption/desorption tests were performed in a lab-scale plant composed of 4 $0.5 \mathrm{~m}$ glass columns (inner diameter $0.0244 \mathrm{~m}$ ) connected in series. A picture and the flow-sheet of the plant are shown in Fig. 1. Each column contained a narrow layer $(0.022 \mathrm{~m})$ of quartz sand both at the bottom and at the top. Therefore, the actual height of XAD16N resin bed was $1.82 \mathrm{~m}$. Indeed, a previous work of PC adsorption from OMW conducted with XAD16N showed that an increase in resin height from 0.5 to $1.8 \mathrm{~m}$ determined an increase in resin operating capacity from $12 \%$ to $43 \%{ }^{23}$ Each column was packed using the dynamic axial compression technique described in detail previously. ${ }^{22}$ All the adsorption / desorption tests object of this work were conducted with the same resin load.

The fluid dynamic behaviour of the adsorption bed was studied before each adsorption /desorption experiment by means of conventional frontal analysis experimental tests conducted with a non-sorbed tracer $(\mathrm{NaCl})$, as illustrated in more detail by Frascari et al. ${ }^{22}$ The main goal of these tests was to estimate the effective porosity $\left(\varepsilon_{\text {resin }}\right)$ and longitudinal dispersivity $\left(\alpha_{L, r e s i n}\right)$ of the resin packed bed. The effective porosity was estimated from the retention time distribution curve, following procedure proposed by Levenspiel. ${ }^{54} \alpha_{L \text {,resin }}$ was estimated by best-fit of the experimental outlet concentrations with the following 1-D convection-dispersion model:

$$
\delta_{i} \cdot \frac{\partial C_{L, i}}{\partial t}=-v_{i n t} \cdot \frac{\partial C_{L, i}}{\partial z}+D_{e q} \cdot \frac{\partial^{2} C_{L, i}}{\partial z^{2}}
$$

where: the retardation factor $\delta_{i}$, equal to $1+K_{e q, i} \rho_{b} / \varepsilon$, was set to 1 due to the lack of $\mathrm{NaCl}$ adsorption on XAD16N; the interstitial velocity $v_{\text {int }}$ was determined as $Q /\left(S_{t} \cdot \varepsilon_{\text {resin }}\right)$ for the resin bed and $Q /\left(S_{t}\right.$ $\cdot \mathcal{E}_{\text {sand }}$ ) for the sand layers (initial and final $22 \mathrm{~mm}$ in each column); the equivalent diffusion coefficient 
$D_{e q}$ was expressed as $\alpha_{L, \text { resin }} \cdot v_{\text {int, resin }}$ or $\alpha_{L, \text { sand }} \cdot v_{\text {int,sand }}$. The integration of Equation (1) was performed with the time-dependent convection/diffusion module of the finite element PDE solver Comsol Multiphysics 3.5a. Estimates of $\varepsilon_{\text {sand }}$ and $\alpha_{L \text {,sand }}$ obtained in preliminary tests and the $\varepsilon_{\text {resin }}$ estimated as described above were used as input values. The best-fit value and 95\% confidence interval of $\alpha_{L, \text { resin }}$ were determined by applying the Gauss-Newton method, following a procedure specifically adapted to convection-dispersion problems. ${ }^{55-57}$ In short, the integration of Equation (1) was repeated for different values of $\alpha_{L \text {,resin }}$ in order to minimize the sum of squared residuals between calculated and experimental $\mathrm{NaCl}$ concentrations at the column outlet. The Gauss-Newton iterative algorithm was stopped when the relative variation in $\alpha_{L, \text { resin }}$ resulted $<10^{-3}$. The tracer tests were also used to estimate the packing quality by means of two indicators: the reduced plate height, calculated as (height equivalent to a theoretical plate) / (mean resin particle diameter), and the asymmetry factor, evaluated as the ratio between the leading and tailing semi-width of the peak of the retention time distribution curve at $10 \%$ of the peak height. More details on the evaluation of these parameters are reported by Frascari et al. ${ }^{22}$ To avoid any potential effect of $\mathrm{NaCl}$ on the subsequent adsorption tests, the 4 columns were fluxed with 2 bed volumes of demineralized water after each frontal analysis test.

\section{Adsorption process: breakthrough tests and simulations}

Six adsorption/desorption breakthrough tests, labelled $\mathrm{T} 1$ to $\mathrm{T} 6$, were performed at room temperature $\left(21-25^{\circ} \mathrm{C}\right)$ in the $1.82-\mathrm{m}$ column in order to identify suitable velocities for both the adsorption and desorption steps to be used for the design of the full-scale plant, and ultimately for the process LCA and CBA. All the six tests were performed with the same load of resin XAD16N, in order to test the resin performances during repeated adsorption/desorption cycles. The operating conditions of each test are reported in Table 2. The experimental scheme included a first group of tests (T1-T3) performed at increasing superficial velocities $(1.2$ to $4.6 \mathrm{~m} / \mathrm{h}$ ), corresponding to hydraulic retention times in the 0.3-1.3 $\mathrm{h}$ range and bed volumes / hour in the $0.7-2.5 \mathrm{BV} / \mathrm{h}$ range. These values were selected on the basis of the results obtained in previous studies of PC adsorption from OMW with resin XAD16N. ${ }^{22,23}$ Conversely, the second group of tests (T4 to T6) were performed approximately at the same velocity and HRT of test $\mathrm{T} 2$, in order to assess the reproducibility of the process performances in repeated tests.

The filtered OMW was fed to the column with a Masterflex L/S 0.1 HP 6-600 RPM peristaltic pump. Pressure drop and temperature were measured hourly. Total PCs and COD were measured in samples taken hourly from the column exit and every 3 hours from the column inlet. Outlet PC and COD normalized concentrations were obtained by dividing the measured concentration by the average PC and COD inlet levels. The tests were monitored up to 20 hydraulic residence times in the resin (determined as $V_{\text {resin }} \cdot \varepsilon_{\text {resin }} / Q$ ), corresponding to an outlet normalized PC concentration varying between 0.16 and 0.34 .

The adsorption performance was quantified by means of the following performance indexes, referred to a 0.20 PC normalized concentration used as breakpoint value:

i) resin operating capacity $\left(\eta_{\text {resin }}\right)$, defined as (PC mass sorbed at the breakthrough point, $m_{P C \text {,adsorbed }}$ / (total PC mass that could be sorbed if all the resin was saturated);

ii) PC and COD adsorption yield $\left(Y_{a d s, i}\right)$, evaluated as $m_{i, \text { adsorbed }} / m_{i, f e d}$;

iii) $\mathrm{PC} / \mathrm{COD}$ adsorption selectivity, expressed as the corresponding adsorption yield ratios.

These indexes were calculated according to the procedure illustrated in Table S1 in the Supporting Information. The 95\% confidence intervals associated to these performance indicators were evaluated as follows: for $Y_{a d s, P C}$ and $Y_{a d s, C O D}$, the approach illustrated by Atkinson and Kendall for integration errors was applied; ${ }^{58}$ for the PC/COD adsorption selectivity, calculated as $Y_{a d s, P C} / Y_{a d s, C O D}$, standard error propagation rules were applied; for $\eta_{\text {resin }}$ a different approach was applied, as the evaluation of this parameter requires the integration of the simulated PC breakthrough curve until the complete resin saturation, well beyond the portion of the PC breakthrough curve for which experimental data were produced in this work; this approach is described in the Results and Discussion, in section "Modelling of the adsorption breakthrough tests". 
In order to evaluate the resin operating capacity obtained in each test, and therefore to identify the optimal operational condition for the process scale-up, LCA and CBA, the experimental normalized PC breakthrough curves were interpreted by means of a 1-D convection-dispersion model. In previous works of PC adsorption from OMW using resin XAD16N, it was shown that a 1D model with equilibrium adsorption was not capable to adequately fit the experimental breakthrough curve. $^{22,23}$ The same works showed that - limitedly to the concentration ranges of interest - the PC isotherms could be effectively interpolated by means of a linear model adsorption model. This simplified adsorption model does not take into account the possible competitive adsorption that could be exerted by the other organic compounds present in the tested OMW. ${ }^{34}$ Therefore, in this work the simulations were performed under the hypothesis of not negligible mass-transfer resistance, expressed by means of an overall volumetric coefficient $k_{L} a$, introducing a linear adsorption model in the term expressing the driving force for solid-liquid mass transfer. The PC normalized concentrations were thus simulated by means of the following mass balance equations, relative to the liquid (Equation 2) and sorbent (Equation 3) phases:

$$
\begin{aligned}
& \frac{\partial C_{L, P C}}{\partial t}=-v_{i n t} \cdot \frac{\partial C_{L, P C}}{\partial z}+D_{e q} \cdot \frac{\partial^{2} C_{L, P C}}{\partial z^{2}}-k_{L} a \cdot\left(C_{L, P C}-\frac{C_{S, P C}}{K_{e q, P C}}\right) \\
& \frac{\rho_{b}}{\epsilon} \cdot \frac{\partial C_{S, P C}}{\partial t}=k_{L} a \cdot\left(C_{L, P C}-\frac{C_{S, P C}}{K_{e q, P C}}\right)
\end{aligned}
$$

where: $C_{L, P C}$ represents the PC liquid phase concentration, $C_{S}, P C$ the solid-phase concentration ( $\mathrm{g}_{\mathrm{PC}} / \mathrm{g}_{\mathrm{dry}}$ resin), $k_{L} a$ the mass-transfer coefficient referred to liquid volume $(1 / \mathrm{h}), \rho_{b}$ the sand or resin bulk density (calculated as mass of dry sand or resin divided by the volume of the corresponding column portion; $\left.\mathrm{kg} / \mathrm{m}^{3}\right), \varepsilon$ the resin or sand porosity (-), $K_{e q, P C}$ the equilibrium adsorption constant $\left(\mathrm{L} / \mathrm{kg}_{\text {dry resin }}\right)$ and $D_{\text {eq }}$ the equivalent diffusion coefficient, calculated as $\alpha_{L, \text { resin }} \cdot v_{\text {int, resin }}$ or $\alpha_{L, \text { sand }} \cdot v_{\text {int,sand }}$. $K_{e q, P C}$ and $k_{L} a$ were estimated by best-fit on the experimental PC concentrations following the GaussNewton method, according to the procedure for its application to convection-dispersion problems described previously. ${ }^{55-57}$ The quality of each best fit was evaluated by means of the correlation coefficient $R^{2}$ as defined previously. ${ }^{59}$

\section{Desorption-regeneration tests}

After each breakthrough adsorption test, acidified ethanol $(0.5 \% \mathrm{v} / \mathrm{v} \mathrm{HCl} 0.1 \mathrm{~N})$ was fed in countercurrent flow with respect to the adsorption step, in order to desorb and recover PCs. In each desorption test, the ethanol velocity was set to $50 \%$ of the OMW velocity of the previous adsorption step. The

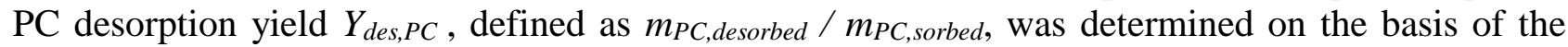
volume and PC content of the ethanol solution. To regenerate the solvent and recover the desorbed compounds, the desorbed extract was fed to a low-pressure rotatory evaporator (LABOROTA 4002 Heidolph, Schwabach, Germany). Before each subsequent adsorption step, the column was rinsed with 1 pore volume of demineralised water in order to remove the residual ethanol.

\section{Life cycle assessment and cost/benefit analysis and of the $\mathrm{PC}$ recovery process}

In order to perform an LCA and CBA of the proposed technology for PC recovery, a scale-up of the adsorption / desorption process was performed, according to the procedure illustrated in the Results and Discussion, in section "Design of the full-scale PC adsorption / desorption process".

Currently, the most frequent solution for the disposal of OMW in European countries is its treatment in a municipal wastewater treatment plant (WWTP). Therefore, the selected benchmark process for the development of both the LCA and CBA was the treatment of raw (undephenolized) OMW in a municipal WWTP. The LCA of the PC recovery process was performed following the stages defined by the ISO 14040 standard: ${ }^{60}$ goal and scope definition, inventory analysis, impact assessment and data interpretation. The goal of the LCA was to identify which components of the plant and process contribute mostly to the overall environmental impact, so as to identify improvement potential. The software SimaPro 8.4.0 and the database Ecoinvent 3.3 were utilized. ${ }^{61,62}$ Five LCA methods were applied and compared (ILCD 2011 Midpoint+ V1.10, IPCC 2013 GWP 20a 
V1.03, Ecological Scarcity 2013 V1.05, Cumulative Energy Demand V1.09, Impact 2002+). For all methods, the selected functional unit was the treatment of $1 \mathrm{~m}^{3}$ of OMW.

The CBA was performed according to the European Union guidelines for the appraisal of investment products. ${ }^{63}$ The starting assumption of the CBA was that a successful commercial implementation of the proposed technology for PC recovery requires a positive financial perspective for the OMW producer (the investor). The goal of the financial CBA was thus to determine the minimum market price at which the recovered PC should be sold, in order to generate a positive business case for the OMW producer. In particular, the weighted-average cost of capital (WACC) was selected as the key threshold in order to determine a positive investment decision. ${ }^{64,65}$ Indeed, the investor has to obtain capital in order to finance the implementation and operation of the PC recovery facility. This means that the cost of capital - in addition to the potential financial sustainability of the project - will determine the willingness of the end-user to invest in the PC recovery installation. The cost of capital of a company can be determined by its blend of debt and equity. As the WACC depends on the individual company's financing structure, it is difficult to establish a generalized WACC that can lead to a positive investment decision. On the basis of the authors' previous experience relative to positive business cases for agricultural companies, in this work the minimum WACC required to generate a positive business case for the OMW producer was set to $6 \%$. The CBA was referred to a 20 -year period, assuming a financial discount rate equal to $4 \%$. The cost of the plant's equipment (CAPEX) was determined by means of the SuperPro Designer® software. The plant's operational and maintenance cost (OPEX) was based on the process inventory illustrated in section "Preliminary design, life cycle assessment and cost-benefit analysis of a fullscale PC adsorption / desorption process", and on the application of standard unit costs for reagents, energy and labor in Europe obtained from the Eurostat database and from the quotations for the price of chemicals obtained from two major suppliers of chemicals. The industrial price of resin XAD16N was provided by the resin supplier (DOW Chemicals). An average $2 \%$ price inflation was applied to correct for price increases to the reference year. The cost relative to the treatment of dephenolized OMW was conservatively assumed equal to the cost of the benchmark process, i.e. of the treatment of raw OMW in a municipal WWTP. Thus, this represents a cost that the OMW producer should sustain in any case, independently of the business choice object of this CBA (i.e., whether or not to invest in a plant for PC recovery from OMW). For this reason, the cost for the treatment of dephenolized OMW was not considered in this CBA.

\section{RESULTS AND DISCUSSION}

\section{Fluid-dynamic characterization of the packed columns}

As a preliminary step, a frontal analysis experimental test was performed before and after each of the 6 adsorption/desorption experiments (T1-T6, Table 2), in order to estimate the effective porosity $\left(\varepsilon_{\text {resin }}\right)$, longitudinal dispersivity $\left(\alpha_{L, \text { resin }}\right)$ and packing quality of the resin packed bed, and to assess the variation of these parameters during 6 consecutive adsorption/desorption tests conducted with the same resin packing. The experimental outlet concentrations of the non-sorbed tracer $(\mathrm{NaCl})$ were simulated with Equation (1), with the retardation factor $\delta$ set to 1. The Gauss Newton method to estimate the longitudinal dispersivity converged after 4-8 iterations, leading to high-quality bestfitting interpolations $\left(R^{2}=0.990-0.999\right)$. As a representative example, the experimental and bestfitting simulated concentrations at the column outlet obtained in the first frontal analysis test are shown in Fig. 2. The effective porosity varied between 0.82 and 0.89 , with an average value equal to $0.86 \pm 0.03$ and without any clear trend during the 6 repeated cycles. This outcome indicates that the OMW centrifugation / filtration pre-treatment was effective in preventing the accumulation of solids in the packed resin, and the consequent possible decrease in resin porosity. The longitudinal dispersivity gradually increased from $0.01 \mathrm{~m}$ to $0.05 \mathrm{~m}$, with an average value equal to $0.034 \pm 0.021$ $\mathrm{m}$. The first test, conducted right after the resin packing, resulted in a high packing quality (asymmetry factor $=1.3$, reduced plate height $=25$ ). The operation of 6 consecutive adsorption/desorption cycles 
led to a modest decrease of the packing quality, with the asymmetry factor and the reduced plate height equal, after the $6^{\text {th }}$ cycle, to 1.8 and 75 respectively.

\section{Adsorption breakthrough tests at different superficial velocities}

The design, LCA and CBA of the full-scale process of PC recovery were based on experimental tests aimed at identifying a suitable superficial velocity for both the adsorption and the desorption step. The operating conditions of the 6 adsorption / desorption tests are reported in Table 2. The tests were continued until the attainment of an outlet PC normalized concentration in the 0.17-0.34 range. Tests $\mathrm{T} 1$ to $\mathrm{T} 3$ were conducted at increasing superficial velocities $(1.2$ to $4.6 \mathrm{~m} / \mathrm{h})$ in order to identify an appropriate velocity and hydraulic retention time in the resin $(H R T)$ for the scale-up of the process, whereas tests T4 to T6 were performed approximately at the same velocity and HRT of T2 - the test that led to the best performances in the first group - in order to assess the reproducibility of the process performances in repeated tests conducted under constant and optimized experimental conditions. The normalized PC concentrations obtained at the column outlet are plotted versus normalized time, defined as (actual time) / (resin HRT), in Fig. 3 for tests T1-T3, and in Fig. 4b for tests T2 and T4-T6 (the 4 repeated tests). In addition, Fig. 4a shows the normalized COD concentrations obtained at the column outlet in tests $\mathrm{T} 2$ and T4-T6. Lastly, Table 2 reports the main performance parameters evaluated, for each test, on the basis of the simulations illustrated in section "Modelling of the adsorption breakthrough tests". Thanks to the effective pre-treatment of OMW centrifugation / filtration, the increase in pressure drop observed during each adsorption test was quite limited: from the initial level of 0.2 bar, corresponding to the hydraulic head, to a final value of $0.4-0.5$ bar. This acceptable increase in pressure drop resulted fully reversible by means of the applied desorption/regeneration procedure.

The scrutiny of Fig. 3 indicates that test T2, conducted at the intermediate velocity $(2.8 \mathrm{~m} / \mathrm{h})$ and HRT $(0.52 \mathrm{~h})$, was characterized by a slower PC release at the column outlet, and therefore a better PC adsorption performance. This observation is confirmed by the higher PC resin operating capacity obtained in T2 (0.47) in comparison with T1 and T3 (0.34-0.39; Table 2). A higher operating capacity determines a lower cost for the periodic resin replacement, as will be illustrated in section "Design of the full-scale PC adsorption / desorption process". Conversely, superficial velocity did not have a significant effect on the PC adsorption yields obtained in T1-T3, which resulted high and very similar (0.90-0.93). The comparison between the PC and COD breakthrough curves reported in Fig. 4 for tests T2 and T4-T6 indicates that, as a result of the high selectivity of resin XAD16N for PCs, COD was characterized by a poor retention in the column, and therefore a rapid release at the column outlet. Coherently with this observation, the COD adsorption yields resulted significantly lower than the PC yields (Table 2). As a consequence, the $Y_{a d s, P C} / Y_{a d s, C O D}$ ratio, that represents an indicator of the resin selectivity for PCs, resulted satisfactory in all the tests, with an overall variation in the 2.9-5.3 range. In agreement with the results of previous studies of PC adsorption from OMW, ${ }^{15,22-25}$ this finding confirms the high affinity of XAD16N for PCs. In particular, in breakthrough tests conducted with resins XAD16N and XAD4 in the 3-12 bed volume / hour range, Zagklis et al. ${ }^{15}$ obtained a $Y_{a d s, P C} / Y_{a d s, \text { carbohydrates }}$ ratio variable between 3 and 4, very close to the range obtained in this study for the $Y_{a d s, P C} / Y_{a d s, C O D}$ ratio. Notably, in the first group of tests (T1-T3), the test operated at the intermediate velocity $(\mathrm{T} 2 ; 2.8 \mathrm{~m} / \mathrm{h})$ resulted not only in the highest PC resin operating capacity, but also in the highest estimate of the resin selectivity for PCs (4.2).

Thanks to the satisfactory performances in terms of resin operating capacity and PC/COD selectivity, the intermediate values of velocity and $H R T(2.8 \mathrm{~m} / \mathrm{h}$ and $0.52 \mathrm{~h}$; test T2) were selected as the optimal ones for the 3 tests (T4-T6) aimed at evaluating the reproducibility of the adsorption/desorption performances in repeated cycles conducted with the same resin load and under roughly constant operational conditions. As shown in Table 2, tests T4-T6 were characterized by $\pm 12 \%$ fluctuations in superficial velocity due to the effect of the variations in pressure drop throughout the repeated adsorption / desorption cycles on the resulting OMW flow rate; however, the average superficial velocity of these tests was equal to that of test $\mathrm{T} 2(2.8 \mathrm{~m} / \mathrm{h})$. As can be observed in Fig. 4b, in the first of these additional tests (T4) a slightly more rapid PC breakthrough was 
obtained, in comparison with that obtained in T2. In T5 and T6, after a further minor shift of the PC curve, the process reached a stable condition. These visual observations are supported by the trend of the resin operating capacity, which resulted roughly equal in T2 and T4 (0.47-0.49), and slightly decreasing in T5 and T6 (0.42-0.45; Table 2). Conversely, the PC and COD adsorption yields, and therefore the resin selectivity for PCs, resulted very stable during the 4 repeated tests (Table 2). The scrutiny of Fig. 4a also indicates that the COD breakthrough curves resulted very rapid and stable during the 4 repeated tests conducted under roughly constant operational conditions.

\section{Modelling of the adsorption breakthrough tests}

The best-fitting simulations of the PC breakthrough curves obtained with the proposed model of nonequilibrium adsorption (Equations (2) and (3)) are reported with continuous lines in Fig. 3 (tests T1T3) and in Fig. 4 (tests T2 and T4-T6), whereas the best-fitting values of $K_{e q, P C}$ and $k_{L} a$ are reported in Table 2, together with the $95 \%$ confidence intervals. The application of the Gauss Newton method to estimate $K_{e q, P C}$ and $k_{L} a$ by best-fit of the proposed model on the experimental PC concentrations led to convergence after 5-6 iterations, to high-quality best-fitting interpolations $\left(R^{2}=0.93-0.98\right)$ and to acceptable $95 \%$ confidence intervals on the estimates of $K_{e q, P C}$ and $k_{L} a$ (average relative $95 \%$ $\mathrm{CI}=9 \%$ for $K_{e q, P C}$ and $15 \%$ for $k_{L} a$; Table 2). In tests T1-T3, the best-fitting values of $K_{e q, P C}$ showed a decreasing trend with temperature. The estimates of $K_{e q, P C}$ reported in Table 2 are likely to be affected by competitive adsorption exerted by the other organic compounds present in the tested OMW, although this aspect was not specifically investigated in this work. As expected, the best estimates of $k_{L} a$ increased with superficial velocity in T1-T3, and resulted quite stable in T4-T6. This result provides a possible justification to the fact that the optimal PC adsorption performance was obtained in the test characterized by the intermediate values of velocity and $H R T$ (T2) and not, as one could expect, in the test operated at the lowest velocity and highest $H R T$ (T1). Indeed, as velocity decreases, the beneficial effect of the increasing $H R T$ is partially offset by the less effective adsorption due to the decreasing $k_{L} a$ values. The results of these simulations indicate that the proposed 1-D model with non-equilibrium adsorption and linear isotherm allowed a high-quality interpolation of the experimental breakthrough curves. Conversely, additional modelling attempts indicated that an equilibrium adsorption model (Equation (1)) completely failed to interpolate the experimental PC data (data not shown).

In order to evaluate the sensitivity of the model to variations of the key parameters $\left(K_{e q, P C}\right.$, $\left.k_{L} a, \alpha_{L, r e s i n}, \varepsilon_{\text {resin }}\right)$ and to assess the uncertainty in the estimate of the resin operating capacity ( $\left.\eta_{\text {resin }}\right)$, a sensitivity analysis was performed according to the procedure illustrated in Table S2 in the Supporting Information. As reported in Table 3, $k_{L} a$ resulted the parameter with the highest impact on $\eta_{\text {resin }}$, followed by $\alpha_{L, \text { resin }}, \varepsilon_{\text {resin }}$ and lastly $K_{e q, P C}$. On the basis of this analysis, the relative $95 \%$ confidence interval associated to each estimate of $\eta_{\text {resin }}$ was taken equal to the maximum variation observed, i.e. $\pm 5.0 \%$.

The PC adsorption performances obtained in this work compare favourably with those reported in previous works of continuous-flow PC adsorption from OMW using the same resin (XAD16N). In a study conducted with a $0.5 \mathrm{~m}$ resin bed height, the decrease in superficial velocity from 1.4 to $0.5 \mathrm{~m} / \mathrm{h}$, with a corresponding increase in $H R T$ from 0.3 to $0.9 \mathrm{~h}$ and decrease in $B V / h$ from 2.9 to 1.0 , determined an increase in resin operating efficiency from 0.12 to 0.17 , without any relevant effect on the PC adsorption yield (0.87-0.88). ${ }^{22}$ In a further study, the resin bed height was increased to $1 \mathrm{~m}$ and the superficial velocity to $2.3 \mathrm{~m} / \mathrm{h}$, with corresponding $H R T$ and $B V / h$ values equal to $0.30 \mathrm{~h}$ and $2.3 \mathrm{BV} / \mathrm{h}$ respectively. These changes determined a marked increase in resin operating efficiency (equal to 0.30) and a small improvement in PC adsorption yield (0.93). ${ }^{24}$ In the optimal condition identified in this study, a further increase in resin bed height (up to $1.82 \mathrm{~m}$ ), combined with a $2.8 \mathrm{~m} / \mathrm{h}$ superficial velocity (corresponding to $H R T$ and $B V / h$ values equal to $0.62 \mathrm{~h}$ and $1.39 \mathrm{BV} / \mathrm{h}$ ), determined a further increase in resin operating efficiency (equal to 0.46 ).

\section{PC desorption tests}


After every breakthrough test, the adsorbed matter was desorbed from the resin by feeding acidified ethanol $(0.5 \% \mathrm{v} / \mathrm{v} \mathrm{HCl} 0.1 \mathrm{M})$. In each desorption, the ethanol flow rate was set to $50 \%$ of the OMW flow rate of the previous adsorption step so as to maintain the total pressure at the column inlet $<1.5$ bars, as solvent viscosity increased due to the increase in PC dissolved concentration. The PC desorption yield $\left(m_{P C \text {,desorbed }} / m_{P C \text {,sorbed }}\right)$ varied in the 0.65-0.75 range, without any clear correlation with ethanol superficial velocity or number of previous cycles. The average PC desorption yield in the optimized condition corresponding to tests T2, T4, T5 and T6 (OMW superficial velocity $=2.8 \mathrm{~m} / \mathrm{h}$; ethanol superficial velocity $=1.4 \mathrm{~m} / \mathrm{h}$ ) resulted equal to 0.71 . As the average $\mathrm{PC}$ adsorption yield in these tests was 0.92 , the average process yield $\left(m_{P C \text {,fed }} / m_{P C, \text { sorbed }}\right.$, evaluated as $\left.Y_{a d s, P C} \cdot Y_{d e s, P C}\right)$ used for the process scale-up was taken equal to 0.65. Each desorption step was stopped upon the achievement of a PC concentration in ethanol at the column outlet equal to $1 \%$ of the average inlet concentration during the adsorption step. The volume of acidified ethanol required to attain this stopping condition varied between $13 \%$ and $17 \%$ of the OMW volume fed during the adsorption step. The average value of the (ethanol volume)/(OMW volume) ratio relative to the optimal condition (tests T2, T4, T5, T6) resulted equal to 0.15. As shown in Table 2, the PC/VS ratio of the desorbed products obtained in the optimized condition (tests T4, T5 and T6) varied between 0.21 and 0.28 gPC$\mathrm{HPLC} / \mathrm{g}_{\mathrm{VS}}$, with an average value equal to $0.26 \mathrm{~g}_{\mathrm{PC}-\mathrm{HPLC}} / \mathrm{g}_{\mathrm{VS}}$. This value is 4.5 times higher than the corresponding ratio in the studied OMW, equal to $0.056 \mathrm{~g}_{\text {PC-HPLC }} / \mathrm{g}_{\mathrm{VS}}$. This result confirms that, thanks to the high affinity of resin XAD16N for PCs, the proposed adsorption / desorption technology leads to a significant enrichment in PCs of the wastewater fed to the process. The non-phenolic fraction of the desorbed product resulted to be composed by carbohydrates $(84 \%)$ and proteins $(16 \%)$, whereas lipids were not detected. The measurement of the product purity by means of the Folin-Ciocalteu method for PCs led to estimate a higher PC content in the desorbed product, equal to $0.44 \mathrm{~g}_{\text {PC-Folin }} / \mathrm{g}_{\mathrm{VS}}$ in average terms. The relevant difference obtained between the PC content measured by HPLC and by Folin-Ciocalteu method can be attributed to the fact that both methods are based on the use of a single response factor (relative to gallic acid, by convention) for the determination of numerous compounds characterized by significantly different response factors. Thus, both methods provide an indication, rather a precise quantification, of the total PC content in the final product. In addition, the Folin-Ciocalteu method could overestimate the total PC concentration, as it is responsive to other antioxidant molecules such as nonphenolic compounds. ${ }^{66,67}$

The attainment of relatively low desorption yields indicates that further research aimed at optimizing the PC desorption process is needed. On the other hand, it is noteworthy that 6 consecutive adsorption / desorption cycles, operated with the same resin load, resulted in roughly constant values in terms of adsorption and desorption yields and resin operating capacity. This outcome indicates that the proposed process for resin regeneration allows the attainment of a stable condition for resin XAD16N. These observations are in agreement with the results of a previous study of PC adsorption with XAD16N and subsequent desorption with acidified ethanol conducted in batch conditions in which, during 10 consecutive adsorption / desorption cycles conducted with the same resin load, the overall yield $\left(Y_{a d s, P C} \cdot Y_{d e s, P C}\right)$ - after an initial minor decrease - stabilized at about 0.40 , even though in a not-optimised single extraction. ${ }^{25}$ Similarly, in a study conducted with resins XAD16N and XAD4, Zagklis et al. ${ }^{15}$ obtained a stable behaviour in terms of final product composition, during 5 consecutive breakthrough tests conducted at 3 bed volumes / hour with the same resin load.

The specific antioxidant activities of the desorbed products obtained in the breakthrough tests varied in the 2.9-6.1 $\mathrm{g}_{\text {ascorbic acid }} / \mathrm{g}_{\mathrm{PC}}$, without any clear correlation with fluid velocity (Table 2 ). These values resulted comparable to that of the OMW fed to the process $\left(4.4 \mathrm{~g}_{\text {ascorbic acid }} / \mathrm{g}_{\mathrm{PC}}\right)$. This outcome shows that the proposed process led to a satisfactory enrichment in PCs of the target OMW, while maintaining approximately the same specific antioxidant activity. The antioxidant capacities of the desorbed products obtained in this work resulted comparable to those measured in single-compound solutions of two PCs characterized by a high antioxidant activity, namely caffeic acid (1.7 gascorbic $_{\text {a }}$ acid $\left./ \mathrm{g}_{\mathrm{PC}}\right)$ and hydroxytyrosol $\left(9.1 \mathrm{~g}\right.$ ascorbic acid $\left./ \mathrm{g}_{\mathrm{PC}}\right),{ }^{24}$ indicating that the proposed process led to a PCrich product characterized by a relatively high antioxidant activity. 


\section{Preliminary design, life cycle assessment and cost-benefit analysis of a full-scale PC adsorption / desorption process}

Design of the full-scale PC adsorption / desorption process

The preliminary sizing of a full-scale plant for OMW filtration, PC adsorption / desorption and desorption solvent recovery represents the basis for providing the input elements required for the LCA and CBA of the process. This section describes the assumptions and procedure on which the plant design is based, as well as the main results. The resulting performance parameters and design values are summarized in Table S3 in the Supporting Information, whereas the resulting elements that represent the input inventory for LCA and CBA are reported in Table S4 in the Supporting Information.

The LCA and CBA were referred to 1 season of olive oil and OMW production. This season generally extends from mid-October to January, with some regional variations. The total OMW volume to be treated during the season was set to $10,000 \mathrm{~m}^{3}$, a typical value for a large size olive mill. The number of adsorption / desorption columns was set to 1, which makes the process necessarily discontinuous: during the desorption step, no OMW adsorption occurs. The OMW flow-rate fed to the plant was set to $4.17 \mathrm{~m}^{3} / \mathrm{h}$, so as to obtain a total treatment time equal to about 4 months, a period comparable to the OMW production period. This choice allows to avoid the costs and environmental impacts associated to the storage of large amounts of OMW.

The use of the same average superficial velocity $(2.78 \mathrm{~m} / \mathrm{h})$ and resin $H R T(0.56 \mathrm{~h})$ of the 4 lab-scale tests operated in the optimal condition (T2 and T4-T6) was applied as scale-up criterion. Therefore, assuming that the full-scale plant and the laboratory plant feature the same resin porosity $(0.857)$, also the interstitial velocity $(3.24 \mathrm{~m} / \mathrm{h})$ and resin bed height $(1.82 \mathrm{~m})$ of the industrial plant resulted equal to the corresponding values of the lab-scale plant. The column diameter of the industrial plant corresponding to a $4.17 \mathrm{~m}^{3} / \mathrm{h}$ resulted equal to $1.38 \mathrm{~m}$.

On the basis of these scale-up choices, it is reasonable to assume that time of the $20 \%$ PC breakpoint $(10.9 \mathrm{~h})$ and the average process performances obtained in the lab-scale plant under the optimal experimental condition at the $20 \%$ breakpoint (adsorption yield 0.922 , desorption yield 0.704 , resin operating capacity 0.456 ) are valid also for the full-scale process.

The dry mass of resin XAD16N to be loaded in the plant, calculated as (volume of resin bed) - (bulk density of the packed resin), resulted equal to $700 \mathrm{~kg}$, corresponding to $975 \mathrm{~L}$ of commercial resin on the basis of the $0.72 \mathrm{~kg} / \mathrm{L}$ shipping density provided by the resin supplier.

The duration of a single adsorption/desorption cycle was calculated as the sum of the duration of the following three steps: i) adsorption, ii) desorption and iii) rinsing with water. The durations of the desorption and water rinsing steps were determined on the basis of the operational conditions and performances assessed in the corresponding steps in the laboratory pilot plant tests, assuming (i) an ethanol volumetric flow rate equal to $Q_{O M W} / 2$ to avoid excessive pressure losses due to the high viscosity of the solvent in the first part of the desorption step, (ii) an (ethanol volume)/(OMW volume) ratio equal to 0.15 , and (iii) a water flow-rate during the water rinsing step equal to the OMW flowrate. The total cycle time and the total time required to treat $10,000 \mathrm{~m}^{3}$ omw resulted equal to $14.7 \mathrm{~h}$ and 4.5 months, respectively. The mass of desorbed PCs produced during the entire production season - a key parameter for the process CBA - was determined as (total OMW volume) $(\mathrm{PC}$ concentration in $\mathrm{OMW}) \cdot($ overall process yield, equal to 0.65 ).

In order to evaluate the mass of resin to be periodically disposed and re-purchased, the number of adsorption / desorption cycles performed with the same resin load was tentatively set to 500, on the basis of indications provided by the resin supplier relative to the industrial practice for resin $\mathrm{XAD} 16 \mathrm{~N}$ in other fields of application. Thus, the duration of each resin load resulted equal to (500 cycles $) \cdot(14.7 \mathrm{~h} /$ cycle $) \approx 300 \mathrm{~d}$, corresponding to about two 4.5 -month seasons of OMW treatment. It should be noted that the resin duration and therefore the periodical cost for periodical resin purchase, increase linearly with the duration of the adsorption step $\left(t_{a d s}\right)$. As shown previously, ${ }^{22}$ the latter parameter is determined by the adsorption performance and, in particular, by the operating capacity and adsorption yield: 


$$
t_{a d s}=\frac{K_{e q, P C} \cdot m_{\text {dry resin }}}{Q_{O M W}} \cdot \frac{\eta_{\text {resin }}}{Y_{a d s, P C}}
$$

Thus, the resin to be disposed and re-purchased for each OMW production season was taken equal to $50 \%$ of the total resin load in the column. The assumption of 500 cycles in the specific case of PC adsorption from OMW should be confirmed by further research.

The quantification of other input elements for the process LCA and CBA needs the definition of the other plant components, in addition to the adsorption / desorption column:

- A microfiltration unit for the removal of suspended solids (SS). Assuming a nearly complete SS removal and an average $3 \mathrm{~kg} / \mathrm{m}^{3} \mathrm{SS}$ concentration in OMW, the mass of waste $\mathrm{SS}$ to be disposed resulted equal to $30 \mathrm{t} / \mathrm{season}$. Considering the high organic content of this waste, anaerobic digestion was selected as the SS treatment method.

- A rotary dryer for the evaporation of ethanol from the desorbed product (total heat to be supplied: $990500 \mathrm{MJ} / \mathrm{season}$ ).

- A gas burner to provide the heat required for ethanol evaporation (required power $=85 \mathrm{~kW}$ ).

- A condenser for the recovery of the evaporated ethanol.

- A cooling tower to reduce to $30{ }^{\circ} \mathrm{C}$ the temperature of the water exiting the condenser. The water volume to be evaporated and consequently re-integrated resulted equal to 405 $\mathrm{m}^{3} /$ season.

The total ethanol volume to be re-integrated, equal to $4.5 \mathrm{~m}^{3} / \mathrm{season}$, resulted from the sum of two contributions: $0.12 \mathrm{~m}^{3} /$ season of ethanol lost with the solid product (assuming a residual $0.5 \%$ ethanol mass fraction in the solid product) and $4.40 \mathrm{~m}^{3} / \mathrm{season}$ of ethanol lost in the inert purge in the condenser. The total $\mathrm{HCl}$ mass to be purchased, evaluated as $\left(0.0182 \mathrm{~kg}_{\mathrm{HCl}} / \mathrm{m}^{3}\right.$ ethanol $) \cdot($ total ethanol volume evaporated), resulted equal to $27 \mathrm{~kg} / \mathrm{season}$. Lastly, the total electricity consumption evaluated on the basis of a 0.40 bar pressure loss in the adsorption step, 0.65 bar pressure loss in the desorption step, $1.15 \mathrm{kWh} / \mathrm{m}^{3}$ OMw consumption for microfiltration and for the other plant's pumps resulted equal to $12000 \mathrm{kWh} /$ season.

\section{Life cycle assessment}

The results of the LCA performed according to the five methods applied (ILCD 2011 Midpoint+ V1.10, Ecological Scarcity 2013 V1.05, IPCC 2013 GWP 20a V1.03, Cumulative Energy Demand $\mathrm{V} 1.09$, Impact 2002+) are summarized in Table 4 in terms of total score per season and per $\mathrm{m}^{3} \mathrm{OMw}$ and relative contribution of the main lifecycle stages to the total score. A more detailed presentation of the output of the four methods is reported in Fig. 5, which includes the relative contribution to the total LCA score of the main impacts related to the plant's operation (periodic re-integration of ethanol, water and resin XAD16N, electricity for pumping, heat for solvent evaporation) and end of life (disposal of plant equipment, wastewater treatment, anaerobic digestion of solid waste). According to the Cumulative Energy Demand method, the operation phase - dominated by electricity and heat for pumping and solvent evaporation - shows the highest influence (85\%) to the total score. A similar result applies to the IPCC Global Warming Potential method, where the energy required for plant operation and the anaerobic digestion of solid waste determine the highest impact to the total score (61\% and $29 \%$, respectively). Three additional damage categories from the Impact 2002+ method are presented in Fig. 5 and Table 4: for human health, wastewater treatment and heat for ethanol evaporation have the highest impact (35\% and $23 \%$, respectively); for ecosystem quality wastewater treatment shows the highest impact (94\%); for resources damage category, heat for ethanol evaporation has the highest impact (57\%). The other two methods (ILCD 2011 Midpoint+ and Ecological Scarcity 2013) are normalizing and aggregating several impact categories into a single indicator. These two methods provide not only a quantification of the total single score environmental impact of the plant's lifecycle stages (infrastructure, operation and end of life, each subdivided into several components as indicated in Fig. 5), but also an indication of how much each life cycle stage and component impacts the different environmental compartments and impact categories taken into consideration (such as human toxic effects, climate change, acidification, ionizing radiations, eutrophication, land use, depletion of water and terrestrial resources, etc.). According to both 
methods, wastewater treatment has the highest impact (44-52\%), followed by infrastructure in the ILCD method (20\%) and heat for ethanol evaporation in the Ecological Scarcity method (26\%).

The ILCD 2011 Midpoint+ method was selected for a more detailed analysis of the results, as it is a widely recognized and harmonized method at European level. ${ }^{68,69}$ As shown in Fig. 6, the process shows an overall environmental burden of $4.6 \mathrm{mPt} / \mathrm{m}^{3}$ OMw. The highest contributions result from the treatment of the residual dephenolized OMW in a WWTP $\left(2.4 \mathrm{mPt} / \mathrm{m}^{3}\right)$, infrastructure $(0.9$ $\left.\mathrm{mPt} / \mathrm{m}^{3}\right)$, electricity for pumping $\left(0.5 \mathrm{mPt} / \mathrm{m}^{3}\right)$, heat for ethanol evaporation $\left(0.3 \mathrm{mPt} / \mathrm{m}^{3}\right)$ and solid waste anaerobic digestion $\left(0.2 \mathrm{mPt} / \mathrm{m}^{3}\right)$. The impact of each life cycle stage and component on the different environmental compartments and aspects taken into consideration in the ILCD 2011 Midpoint+ and Ecological Scarcity methods are reported in Table S5 and S6 in the Supporting Information.

According to the ILCD 2011 Midpoint+ method, the overall environmental impact of the process of PC recovery and disposal of the dephenolized OMW (4.6 $\left.\mathrm{mPt} / \mathrm{m}^{3} \mathrm{OMW}\right)$ resulted equal to about twice the impact of the benchmark process, i.e. of the treatment of raw OMW in a municipal WWTP. The latter was assumed equal to the average impact of wastewater treatment in Europe (2.4 $\mathrm{mPt} / \mathrm{m}^{3}$ OMw). However, the results indicate that there is a large potential to improve the process environmental performance by adding an additional treatment step - such as anaerobic digestion - to make the treated OMW reusable for irrigation, instead of sending it to a WWTP. Furthermore, anaerobic digestion would produce energy that could cover the process energy demand, and the solid waste produced by OMW microfiltration could be integrated in the anaerobic digestion process to produce a digestate usable as fertilizer. Preliminary evaluations indicates that this solution would lead to an overall environmental impact lower than that of the selected benchmark process.

Several studies conducted LCA of the whole olive oil supply chain and the phase with the greatest impact is the agricultural one in almost all the impact categories. ${ }^{70}$ Regarding the olive oil extraction phase, the processing stage shows highest impact especially due to the effluent disposal to evaporation ponds. ${ }^{71}$ A limited number of studies report the LCA of processes for OMW treatment or for PC recovery. ${ }^{16,43,72}$ However, these studies focus on different techniques (extraction), apply different system boundaries (end of life not always considered) and consider different food byproducts, in comparison to this work. ${ }^{16,43,72}$ Even though a direct comparison with our results is not feasible due to the different scopes, methods and functional units, energy and solvent requirements are generally the main contributors to environmental impacts, which also applies to the current work if one does not consider the treatment of the residual wastewater.

\section{Cost benefit analysis}

The total cost of the PC recovery process referred to a 20 -year period resulted equal to $531950 €$, of which $48 \%$ was represented by the CAPEX and $52 \%$ by the OPEX. The analysis of the relative contribution of the single CAPEX and OPEX elements to the total cost, shown in Table 5, indicates in the first place that the resin periodic replacement represents the main cost item (25\%). Further research aimed at testing sorbents characterized by high performances and low costs is therefore recommended. In terms of CAPEX, the adsorption column, the solvent evaporation equipment and the solvent condensation / recovery equipment contribute in a similar way to the total capital cost.

The total required revenues were determined by assuming a minimal required internal rate of return equal to the selected WACC threshold, i.e. $6 \%$. The required total revenues were therefore determined as the cash inflows required to matching the total outflows (CAPEX + OPEX) with an internal rate of return of $6 \%$. The resulting total revenue from PC sales during the 20-year period was equal to $875000 €$ (absolute value, not discounted to net present value). Assuming that the total revenues are evenly distributed over the years, this corresponds to an annual revenue of $43750 € / y$. The resulting required PC market price depends on the PC amount produced per year. In order to develop a CBA applicable to different OMW types, and not only to the relatively light OMW object of this work, the PC concentration in OMW was assumed to vary over the $0.5-4 \mathrm{~g} / \mathrm{L}$ range. Consequently, the mass of desorbed PCs produced each year varied in the 3.3-26 tPC/y range. As shown in Fig. 7, the resulting PC market price required to generate a positive business case varies in 
the $1.7-13.5 € / \mathrm{kg}$ range, depending on the PC content in OMW. Considering that the market price of PC-rich products varies in the $250-2500 € / \mathrm{kg}_{\mathrm{PC}},{ }^{73}$ even though a further refining is certainly required for the PC-rich product object of this study, the resulting price range for the generation of a positive business case is likely to be a realistic one.

\section{CONCLUSIONS}

- In this work a full-scale plant of PC adsorption and desorption capable to treat $10000 \mathrm{~m}^{3} \mathrm{OMw}$ in each production season was designed, on the basis of the optimal operational conditions identified by means of lab-scale continuous-flow tests. The full-scale plant design set the basis for the LCA and CBA of the proposed technology.

- The comparison of 5 alternative LCA methods indicated that the highest environmental burdens are due to the treatment of the dephenolized OMW and of the filtered suspended solids, to the heat required to evaporate the desorption solvent, to the electric consumption of the process and to the need of a periodic ethanol reintegration. The overall environmental burden could be significantly reduced through the addition of an anaerobic digestion step for the production of irrigation-quality water and fertilizers from the dephenolized OMW.

- The cost analysis of the proposed technology indicated that the PC market price required for the generation of a positive business case $\left(1.7-13.5 € / \mathrm{kg}_{\mathrm{PC}}\right)$ is a reasonable one, and that therefore the proposed process for PC adsorption has chances to find a successful implementation in Mediterranean regions characterized by a relevant OMW production.

- The lab-scale continuous-flow tests of PC adsorption indicated that a $0.56 \mathrm{~h}$ retention time in a $1.82 \mathrm{~m}$ column packed with resin XAD16N (2.8 m/h superficial velocity, $1.5 \mathrm{BV} / \mathrm{h})$ allowed the attainment of satisfactory performances in terms of resin operating capacity (0.46), PC adsorption yield (0.92), PC/COD selectivity (4.6) PC mass fraction in the sorbed product $\left(0.44 \mathrm{~g}_{\mathrm{PC}} / \mathrm{g}_{\mathrm{VS}}\right)$ and specific antioxidant activity of the final product (3-6 $\mathrm{g}_{\text {ascorbic acid }} / \mathrm{g}_{\mathrm{PC}}$ ).

- Six consecutive adsorption / desorption cycles, operated with the same resin load, resulted in roughly constant values in terms of adsorption and desorption yields and resin operating capacity.

\section{List of abbreviations}

$\begin{array}{ll}\text { BV/h } & \text { Bed volumes per hour } \\ \text { CAPEX } & \text { Capital expenditure } \\ \text { CBA } & \text { Cost-benefit analysis } \\ \text { COD } & \text { Chemical oxygen demand } \\ \text { HRT } & \text { Hydraulic retention time } \\ \text { LCA } & \text { Life cycle assessment } \\ \text { OMW } & \text { Olive mill wastewater } \\ \text { OPEX } & \text { Operational expenditure } \\ \text { PC } & \text { Phenolic compound } \\ \text { SS } & \text { Suspended solids } \\ \text { VS } & \text { Volatile solids } \\ \text { WACC } & \text { Weighted average cost of capital } \\ \text { WWTP } & \text { Wastewater treatment plant }\end{array}$

\section{Nomenclature}

$C_{L, i} \quad$ Liquid phase concentration of compound $i(\mathrm{mg} / \mathrm{L})$

$C_{S, i} \quad$ Solid phase (resin) concentration of compound $i\left(\mathrm{mg} / \mathrm{g}_{\text {dry resin }}\right)$

$D_{e q} \quad=\alpha_{L} \cdot v_{\text {int }}$. Equivalent diffusion coefficient $\left(\mathrm{m}^{2} / \mathrm{s}\right)$

$D_{m o l} \quad$ Diffusion coefficient $\left(\mathrm{m}^{2} / \mathrm{s}\right)$

$K_{\text {eq,i }}=C_{S, i, e q} / C_{L, i, e q}$. Adsorption constant of compound $i$, defined as the slope of the linear portion of the isotherm ( $\left.\mathrm{L}_{\text {pore volume }} / \mathrm{kg}_{\text {dry resin }}\right)$ 


\begin{tabular}{|c|c|}
\hline$k_{L} a$ & Mass transfer coefficient referred to liquid volume (1/s) \\
\hline$m_{d r y}$ resin & Mass of dry resin loaded in the adsorption column (g) \\
\hline$m_{i, f e d, 20 \%}$ & Mass of compound $i$ fed to the column until the $20 \%$ breakpoint (mg) \\
\hline$m_{i, \text { sorbed, } 20 \%}$ & Mass of compound $i$ adsorbed by the resin at the $20 \%$ breakpoint (mg) \\
\hline$Q$ & Volumetric flow rate through the column $\left(\mathrm{m}^{3} / \mathrm{s}\right)$ \\
\hline$S_{t}$ & Transversal section of the column $\left(\mathrm{m}^{2}\right)$ \\
\hline$v_{\text {int }}$ & Interstitial velocity $(\mathrm{m} / \mathrm{s})$ \\
\hline$v_{\text {sup }}$ & Superficial velocity, calculated as $(\mathrm{Q} /$ column section $)$ and equal to $v_{\text {int }} \cdot \varepsilon(\mathrm{m} / \mathrm{s})$ \\
\hline$Y_{a d s, i}$ & $\begin{array}{l}\text { Adsorption yield of compound } i \text {, calculated as } m_{i, \text { sorbed,20\% }} / m_{i, f e d, 20 \%} \text { in the } \\
\text { breakthrough tests (-) }\end{array}$ \\
\hline$Y_{\text {des }, i}$ & $\begin{array}{l}\text { Desorption yield of compound } i \text { in a breakthrough test, defined as } m_{P C \text {,desorbed }} / \\
m_{P C \text {,sorbed }}(-)\end{array}$ \\
\hline$\alpha_{L}$ & Longitudinal dispersivity (m) \\
\hline$\delta_{i}$ & Retardation factor of compound $i(-)$ \\
\hline$\varepsilon_{i}$ & Effective porosity of component $i$ (resin or sand) (-) \\
\hline$\eta_{\text {resin }}$ & $=m_{P C, \text { sorbed }, 20 \%} / m_{P C, \text { sorbed, sat } .}$ Resin utilization efficiency (-) \\
\hline$\rho_{b}$ & Resin bulk density (kg/L) \\
\hline
\end{tabular}

\section{Research data}

Research data underlying this manuscript have been published in the AMS Acta Institutional Research Repository (doi: 10.6092/unibo/amsacta/6028).

\section{Acknowledgements}

This project has received funding from the EU Horizon 2020 research and innovation program under grant agreement No. 688320 (MADFORWATER project; www.madforwater.eu).

\section{References}

1 Dermeche S, Nadour M, Larroche C, Moulti-Mati F and Michaud P, Olive mill wastes: biochemical characterizations and valorization strategies. Process Biochem 48:1532-1552 (2013).

2 Davies LC, Vilhena AM, Novais JM and Martins-Dias S, Olive mill wastewater characteristics: modelling and statistical analysis. Grasas Aceites 55:233-241 (2004).

3 Bertin L, Ferri F, Scoma A, Marchetti L and Fava F, Recovery of high added value natural polyphenols from actual olive mill wastewater through solid phase extraction. Chem Eng $J$ 171:1287-1293 (2011).

4 Yangui T, Sayadi S, Gargoubi A and Dhouib A, Fungicidal effect of hydroxytyrosol-rich preparations from olive mill wastewatera gainst Verticillium dahlia. Crop Protection 29:12081213 (2010).

5 Rahmanian N, Jafari SM and Galanakis CM, Recovery and removal of phenolic compounds from olive mill wastewater. J Am Oil Chem Soc 91:1-18 (2014).

6 Pekin G, Haskök S, Sargın S, Gezgin Y, Eltem R, İkizoğlu E, Azbar N and Sukan FV, Anaerobic digestion of Aegean olive mill effluents with and without pretreatment. J Chem Technol Biotechnol 85:976-982 (2010).

7 Frascari D, Zanaroli G, Abdel Motaleb M, Annen G, Belguith K, Borin S, Choukr-Allah R, Gibert C, Jaouani A, Kalogerakis N, Karajeh F, Ker Rault PA, Khadra R, Kyriacou S, Li WT, Molle B, Mulder M, Oertlé E and Varela Ortega C, Development and application of integrated technological and management solutions for wastewater treatment and efficient reuse in 
agriculture tailored to the needs of Mediterranean African Countries. Integr Environ Assess 14:447-462 (2018).

8 Rodis PS, Karathanos VT and Mantzavinou A, Partitioning of olive oil antioxidants between oil and water phases. J Agric Food Chem 50:596-601 (2002).

9 Tuck L and Hayball PJ, Major phenolic compounds in olive oil: metabolism and health effects. J Nutr Biochem 13:636-644 (2002).

10 Rodriguez-Mateos A, Vauzour D, Krueger CG, Shanmuganayagam D, Reed J, Calani L, Mena P, Del Rio D and CrozierA, Bioavailability, bioactivity and impact on health of dietary flavonoids and related compounds: an update. Arch Toxicol 88:1803-1853 (2014).

11 Del Rio D, Rodriguez-Mateos A, Spencer JP, Tognolini M, Borges G and Crozier A, Dietary (poly)phenolics in human health: structures, bioavailability, and evidence of protective effects against chronic diseases. Antioxid Redox Signal 18:1818-1892 (2013).

12 Reboredo-Rodriguez P, Varela-Lopez A, Forbes-Hernandez TY, Gasparrini M, Afrin S, Cianciosi D, Zhang J, Manna PP, Bompadre S, Quiles JL, Battino M and Giampieri F, Phenolic compounds isolated from olive oil as nutraceutical tools for the prevention and management of cancer and cardiovascular diseases. Int J Mol Sci 19:2305 (2018).

13 El-Abbassi A, Kiai H, and Hafidi A, Phenolic profile and antioxidant activities of olive mill wastewater. Food Chem 132:406-412 (2012).

14 Fortes C, García-Vilas JA, Quesada AR and Medina MA, Evaluation of the anti-angiogenic potential of hydroxytyrosol and tyrosol, two bio-active phenolic compounds of extra virgin olive oil, in endothelial cell cultures. Food Chem 134:134-140 (2012).

15 Zagklis DP, Vavouraki AI, Kornaros ME and Paraskeva CA, Purification of olive mill wastewater phenols through membrane filtration and resin adsorption/desorption, $J$ Hazard Mater 285:69-76 (2015).

16 Kalogerakis N, Politi M, Foteinis S, Chatzisymeon E and Mantzavinos D, Recovery of antioxidants from olive mill wastewaters: a viable solution that promotes their overall sustainable management. J Environ Manage 128:749-758 (2013).

17 Papaphilippou PC, Yiannapas C, Politi M, Daskalaki VM,Michael C, Kalogerakis N, Mantzavinos D and Fatta-Kassinos D, Sequential coagulation-flocculation, solvent extraction and solar-Fenton oxidation for the valorization and treatment of olive mill effluent. Chem. Eng. J 224:82-88 (2013).

18 Galanakis CM, Tornberg E and Gekas V, Recovery and preservation of phenols from olive waste in ethanolic extracts. J Chem Technol Biotechnol 85:1148-1155 (2010).

19 Klen TJ and Vodopivec BM, Ultrasonic extraction of phenols from olive mill wastewater: comparison with conventional methods. J Agr Food Chem 59:12725-12731 (2011).

20 El-Abbassi A, Kiai H, Raiti J and Hafidi A, Cloud point extraction of phenolic compounds from pretreated olive mill wastewater. J Environ Chem Eng 2:1480-1486 (2014).

21 Paraskeva P and Diamadopoulos E, Technologies for olive mill wastewater (OMW) treatment: a review, J Chem Technol Biotechnol 81:1475-1485 (2006)

22 Frascari D, Molina Bacca AE, Zama F, Bertin L, Fava F and Pinelli D, Olive Mill Wastewater Valorisation through Phenolic Compounds Adsorption in a Continuous Flow Column. Chem Eng J 283:293-303 (2016).

23 Pinelli D, Molina Bacca AE, Kaushik A, Basu S, Nocentini M, Bertin L and Frascari D, Batch and continuous flow adsorption of phenolic compounds from olive mill wastewater: a comparison between nonionic and ion exchange resins. Int J Chem Eng 2016: article ID 9349627 (2016).

24 Frascari D, Rubertelli G, Arous F, Ragini A, Bresciani L, Arzu A and Pinelli D, Valorisation of olive mill wastewater by phenolic compounds adsorption: development and application of a procedure for adsorbent selection. Chem Eng J 360:124-138 (2019).

25 Scoma A, Pintucci C, Bertin L, Carlozzi P and Fava F, Increasing the large scale feasibility of a solid phase extraction procedure for the recovery of natural antioxidants from olive mill wastewaters. Chem Eng J 198-199:103-109 (2012). 
26 Jiang X, Yang W, Zhou C, Lu K and Lin C, Separation and purification of polyphenols from pericarpium granati using macroporous resins and evaluation of its anti-streptococcus mutans activity in vitro. Biotechnology 15:86-95 (2016).

27 Agalias A, Magiatis P, Skaltsounis AL, Mikros E, Tsarbopoulos A, Gikas E, Spanos I and Manios T, A new process for the management of olive oil mill waste water and recovery of natural antioxidants. J Agric Food Chem 55:2671-2676 (2007).

28 El Idrissi M, Molina Bacca AE, Frascari D, Corvini PFX and Shahgaldian P, Cyclodextrinbased polymeric materials for the specific recovery of polyphenolic compounds through supramolecular host-guest interactions. J Incl Phenom Macrocycl Chem 88:35-42 (2017).

29 Aliakbarian B, Casazza AA AND Perego P, Kinetic and isotherm modelling of the adsorption of phenolic compounds from olive mill wastewater onto activated carbon. Food Technol Biotechnol 53:207-214 (2015).

30 Ochando-Pulido JM, Gonzalez-Hernandez R and Martinez-Ferez A, On the effect of the operating parameters for two-phase olive-oil washing wastewater combined phenolic compounds recovery and reclamation by novel ion exchange resins. Sep Purif Technol 195: 5059 (2018).

31 Soto ML, Moure A, Domínguez H and Parajó JC, Recovery, concentration and purification of phenolic compounds by adsorption: a review. J Food Eng 105:1-27 (2011).

32 Kammerer J, Carle R and Kammerer DR, Adsorption and ion exchange: basic principles and their application in food processing. J Agric Food Chem 59:22-42 (2011).

33 Bertin L, Frascari D, Domínguez H, Falqué E, Riera Rodriguez FA and Alvarez Blanco S, Conventional purification and isolation, in Food Waste Recovery: Processing Technologies and Techniques, ed. by Galanakis CM. Elsevier - Academic Press, London, UK, pp 149-172 (2015).

34 Kammerer J, Kammerer DR and Carle R, Impact of saccharides and amino acids on the interaction of apple polyphenols with ion exchange and adsorbent resins. J Food Eng 98:230 239 (2010).

35 Kammerer DR, Carle R, Stanley RA and Saleh ZS, Pilot-scale resin adsorption as a means to recover and fractionate apple polyphenols. J Agric Food Chem 58:6787-6796 (2010).

36 Buran TJ, Sandhu AK, Li Z, Rock CR, Yang WW and Gu L, Adsorption/desorption characteristics and separation of anthocyanins and polyphenols from blueberries using macroporous adsorbent resins. J Food Eng 128:167-173 (2014).

37 Otero M, Zabkova $\mathrm{M}$ and Rodrigues AE, Phenolic wastewaters purification by thermal parametric pumping: modeling and pilot-scale experiments. Water Res 39:3467-3478 (2005).

38 Victor-Ortega MD, Ochando-Pulido JM and Martinez-Ferez A, Performance and modeling of continuous ion exchange processes for phenols recovery from olive mill wastewater. Process Saf Environ 100: 242-251 (2016).

39 Victor-Ortega MD, Ochando-Pulido JM, Airado-Rodriguez D and Martinez-Ferez A, Experimental design for optimization of olive mill wastewater final purification with Dowex Marathon C and Amberlite IRA-67 ion exchange resins. J Ind Eng Chem 34: 224-232 (2016).

40 Conidi C, Rodriguez-Lopez AD, Garcia-Castello EM and Cassano A, Purification of artichoke polyphenols by using membrane filtration and polymeric resins. Sep Purif Technol 144: 153161 (2015).

41 Zagklis DP and Paraskeva CA, Purification of grape marc phenolic compounds through solvent extraction, membrane filtration and resin adsorption/desorption. Sep Purif Technol 156: 328335 (2015).

42 Rajkumar D, Palanivelu K and Balasubramanian N, Combined electrochemical degradation and activated carbon adsorption treatments for wastewater containing mixed phenolic compounds. J Environ Eng Sci 4: 1-9 (2005).

43 Todd $\mathrm{R}$ and Baroutian $\mathrm{S}$, A techno-economic comparison of subcritical water, supercritical $\mathrm{CO}_{2}$ and organic solvent extraction of bioactives from grape marc. J Clean Prod 158: 349-358 (2017). 
44 La Scalia G, Micale R, Cannizzaro L and Marra FP, A sustainable phenolic compound extraction system from olive oil mill wastewater. J Clean Prod 142: 3782-3788 (2017).

45 Ioannou-Ttofa L, Michael-Kordatou I, Fattas SC, Eusebio A, Ribeiro B, Rusan M, Amer ARB, Zuraiqi S, Waismand M, Linder C, Wiesman Z, Gilron J and Fatta-Kassinos D, Treatment efficiency and economic feasibility of biological oxidation, membrane filtration and separation processes, and advanced oxidation for the purification and valorization of olive mill wastewater. Water Res 114: 1-13 (2017).

46 Farías-Campomanes AM, Rostagno MA and Meireles MAA, Production of polyphenol extracts from grape bagasse using supercritical fluids: Yield, extract composition and economic evaluation. J Supercrit Fluid 77: 70- 78 (2013).

47 Serrano A, Fermoso FG, Rodríguez-Gutierrez G, Fernandez-Bolaños J and Borja R, Biomethanization of olive mill solid waste after phenols recovery through low-temperature thermal pre-treatment. Waste Manage 61: 229-235 (2017).

48 Folin $\mathrm{O}$ and Ciocalteu V, On tyrosine and tryptophane determinations in protein. J. Biol. Chem. 73: 627-650 (1927).

49 Bradford MM, A rapid and sensitive method for the quantitation of microgram quantities of protein utilizing the principle of protein-dye binding. Anal Biochem 72: 248-254 (1976).

50 Miller GL, Use of dinitrosalicylic acid reagent for determination of reducing sugar. Anal Chem 31: 426-428 (1959).

51 Fernández-Bolaños JF, Rodríguez G, Rodríguez R, Guillén R and Jiménez A, Extraction of interesting organic compounds from olive oil waste. Grasas Aceites 57: 95-106 (2006).

52 Allouche N, Fki I and Sayadi S, Toward a high yield recovery of antioxidants and purified hydroxytyrosol from olive mill wastewaters. J Agric Food Chem 52: 267-273 (2004).

53 Paredes C, Cegarra J, Roig A, Sfinchez-Monedero MA and Bernal MP, Characterization of olive mill wastewater (alpechin) and its sludge for agricultural purposes. Biores Technol 67: 111-115 (1999).

54 Levenspiel O, Chemical Reaction Engineering, third ed., Wiley, New York, USA (1999).

55 Zama F, Ciavarelli R, Frascari D and Pinelli D, Numerical parameter estimation in models of pollutant transport with chemical reaction, in System Modeling and Optimization, IFIP Advances in Information and Communication Technology, vol 391, ed. by Homberg D and Troltzsch F, Springer, Heidelberg, Germany, pp 547 - 556 (2013).

56 Zama F, Frascari D, Pinelli D and Molina Bacca AE, Parameter estimation algorithms for kinetic modeling from noisy data, in System Modeling and Optimization, IFIP Advances in Information and Communication Technology, vol. 494, ed. by Bociu L, Désidéri JA and Habbal A, Springer, Heidelberg, Germany, pp. 517 - 527 (2016).

57 Frascari D, Pinelli D, Ciavarelli R, Nocentini M and Zama F, Chloroform aerobic cometabolic biodegradation in a continuous-flow reactor: model calibration by means of the Gauss-Newton method. Can J Chem Eng, in press (2018).

58 Atkinson KE, An Introduction to Numerical Analysis, John Wiley \& Sons, New York, USA (1989).

59 Frascari D, Fraraccio S, Nocentini M and Pinelli D, Trichloroethylene aerobic cometabolism by suspended and immobilized butane-growing microbial consortia: a kinetic study. Biores Technol 1244:529-538 (2013).

60 ISO 14040, Environmental Management - Life Cycle Assessment - Principles and Framework. International Organisation for Standardisation (ISO), Geneve, Swisse (2006).

61 PRé Consultants, SimaPro 8, Life-cycle Assessment Software Package, Version 8.4.0. Printerweg, Amersfoort, Netherlands (2006).

62 Wernet G, Bauer C, Steubing B, Reinhard J, Moreno-Ruiz E and Weidema B, The ecoinvent database version 3 (part I): overview and methodology. Int J Life Cycle Assess 21:1218-1230 (2016). 
63 European Commission, Guide to Cost-Benefit Analysis of Investment Projects, Economic appraisal tool for Cohesion Policy 2014-2020. Publication Office of the European Union, Luxemburg (2014).

64 Miles JA and Ezzell JR, The weighted average cost of capital, perfect capital markets, and project life: a clarification. J Financ Quant Anal 15:719-730 (1980).

65 Gitman LJ and Mercurio VA, Cost of capital techniques used by major U.S. firms: survey and analysis of fortune's 1000. Financ Manage 11:21-29 (1982).

66 Perez-Jimenez J, Neveu V, Vos F and Scalbert A, Identification of the 100 richest dietary sources of polyphenols: an application of the Phenol-Explorer database. Eur J Clin Nutr 64: S112-120 (2010).

67 Magalhaes LM, Segundo MA, Reis S and Lima JL, Methodological aspects about in vitro evaluation of antioxidant properties. Anal Chim Acta 613: 1-19 (2008).

68 JRC European commission, ILCD Handbook: Recommendations for Life Cycle Impact Assessment in the European context. Publication Office of the European Union, Luxemburg (2011).

69 Huppes G and Van Oers L, Evaluation of weighting methods for measuring the EU-27 overall environmental impact. Publication Office of the European Union, Luxemburg (2011).

70 Salomone R, Cappelletti G M, Malandrino O, Mistretta M, Neri E, Nicoletti GM, Notarnicola B, Pattara C, Russo C and Saija G. Life cycle assessment in the olive oil sector, in Life Cycle Assessment in the Agri-food Sector, Springer International Publishing, Cham, pp 57-121 (2015).

71 Avraamides $\mathrm{M}$ and Fatta D, Resource consumption and emissions from olive oil production: a life cycle inventory case study in Cyprus. J Clean Prod 16: 809-821 (2008).

72 Chatzisymeon E, Foteinis S, Mantzavinos D and Tsoutsos T, Life cycle assessment of advanced oxidation processes for olive mill wastewater treatment. J Clean Prod 54:229-234 (2013).

73 Ciriminna R, Meneguzzo F, Fidalgo A, Ilharco LM and Pagliaro M, Extraction, benefits and valorization of olive polyphenols. Eur J Lipid Sci Technol 118: 503-511 (2016). 
Table 1. Main characteristics of the tested OMW

\begin{tabular}{ll}
\hline Total phenolic compounds ( $\mathrm{g}_{\mathrm{AG}}$ eq./L, HPLC method) & 0.51 \\
Total phenolic compounds (gag $/ \mathrm{L}$, Folin-Ciocalteu method) & 1.1 \\
Total solids (g/L) & 13 \\
Suspended solids (g/L) & 3.0 \\
Dissolved solids (g/L) & 10 \\
Dissolved volatile solids (g/L) & 9.1 \\
Dissolved COD (g/L) & 21 \\
Reducing sugars (g/L) & 1.0 \\
Proteins (g/L) & 1.4 \\
Density $(\mathrm{kg} / \mathrm{L})$ & 1.0 \\
$\mathrm{pH}$ & 4.6 \\
\hline
\end{tabular}


Table 2. Experimental conditions, adsorption/desorption performances and best-fitting parameters relative to the breakthrough tests, with $95 \%$ confidence intervals

\begin{tabular}{|c|c|c|c|c|c|c|c|}
\hline & Parameter & Test ID & & & & & \\
\hline & & $\mathrm{T} 1$ & $\mathrm{~T} 2$ & $\mathrm{~T} 3$ & $\mathrm{~T} 4$ & T5 & T6 \\
\hline & Resin bed height $(\mathrm{m})$ & 1.82 & 1.82 & 1.82 & 1.82 & 1.82 & 1.82 \\
\hline & Adsorption superficial velocity $(\mathrm{m} / \mathrm{h})$ & $1.2 \pm 0.1$ & $2.8 \pm 0.1$ & $4.58 \pm 0.06$ & $2.4 \pm 0.1$ & $3.05 \pm 0.02$ & $2.8 \pm 0.1$ \\
\hline & Hydraulic retention time (h) & $1.3 \pm 0.1$ & $0.52 \pm 0.02$ & $0.34 \pm 0.02$ & $0.60 \pm 0.04$ & $0.49 \pm 0.02$ & $0.55 \pm 0.02$ \\
\hline$\stackrel{\varrho}{\Xi}$ & Bed volumes / hour $(\mathrm{BV} / \mathrm{h}, 1 / \mathrm{h})$ & $0.67 \pm 0.04$ & $1.56 \pm 0.05$ & $2.52 \pm 0.03$ & $1.34 \pm 0.08$ & $1.68 \pm 0.04$ & $1.53 \pm 0.04$ \\
\hline 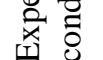 & $\mathrm{T}\left({ }^{\circ} \mathrm{C}\right)$ & $25.0 \pm 0.5$ & $21.0 \pm 0.5$ & $23.0 \pm 0.5$ & $21.0 \pm 0.5$ & $24.0 \pm 0.5$ & $21.0 \pm 0.5$ \\
\hline$\stackrel{0}{g}$ & Resin operating capacity $\left(\eta_{\text {resin }},-\right)^{\mathrm{a}, \mathrm{b}}$ & 0.39 & 0.47 & 0.34 & 0.49 & 0.45 & 0.42 \\
\hline$\sum_{0 \infty}^{\pi}$ & PC adsorption yield $\left(Y_{a d s, P C},-\right)^{\mathrm{a}}$ & $0.93 \pm 0.04$ & $0.92 \pm 0.04$ & $0.90 \pm 0.04$ & $0.93 \pm 0.04$ & $0.92 \pm 0.04$ & $0.92 \pm 0.04$ \\
\hline$\stackrel{\Xi}{\Xi}$ & COD adsorption yield $\left(Y_{a d s, C O D},-\right)^{\mathrm{a}}$ & $0.32 \pm 0.07$ & $0.22 \pm 0.05$ & $0.29 \pm 0.06$ & $0.18 \pm 0.04$ & $0.23 \pm 0.05$ & $0.20 \pm 0.04$ \\
\hline & Resin selectivity for PCs $(-)^{\mathrm{a}, \mathrm{c}}$ & $2.9 \pm 0.6$ & $4.2 \pm 0.9$ & $3.1 \pm 0.7$ & $5.3 \pm 1.2$ & $4.0 \pm 0.9$ & $4.7 \pm 1.1$ \\
\hline $\overrightarrow{0}$ & $K_{\text {eq,PC }}\left(\mathrm{L}_{\text {pore volume }} / \mathrm{kg}_{\text {dry resin }}\right)$ & $100 \pm 6$ & $160 \pm 12$ & $149 \pm 11$ & $124 \pm 11$ & $111 \pm 9$ & $127 \pm 10$ \\
\hline ठ․ & $k_{L} a \cdot 10^{3}(1 / \mathrm{s})$ & $1.3 \pm 0.3$ & $3.2 \pm 0.4$ & $3.5 \pm 0.5$ & $3.1 \pm 0.4$ & $3.1 \pm 0.5$ & $2.6 \pm 0.3$ \\
\hline 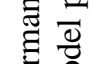 & Purity of the desorbed product $\left(\mathrm{g}_{\mathrm{PC}} / \mathrm{g}_{\mathrm{VS}}\right)^{\mathrm{d}}$ & d n.a. & n.a & n.a & $0.28 \pm 0.06$ & $0.21 \pm 0.05$ & $0.28 \pm 0.05$ \\
\hline 苛 & $\begin{array}{l}\text { Antioxidant capacity of the desorbed } \\
\text { product }\left(\mathrm{g}_{\text {ascorbic acid }} / \mathrm{g}_{\mathrm{PC}}\right)\end{array}$ & 125 & $4.9 \pm 0.2$ & $2.9 \pm 0.1$ & n.a. & $6.1 \pm 0.3$ & $3.4 \pm 0.2$ \\
\hline
\end{tabular}

${ }^{a}$ Evaluated at a $20 \%$ PC outlet normalized concentration.

b The relative 95\% confidence interval of the resin PC operating capacity, evaluated only for the optimal condition corresponding to the average velocity and HRT between tests T2, T4, T5 and T6, resulted equal to $5 \%$.

${ }^{\mathrm{c}}$ Evaluated as $Y_{a d s, P C} / Y_{a d s, C O D}$.

${ }^{\mathrm{d}}$ The reported PC/VS values are based on the measurement of PC concentration by means of the HPLC method.

n.a., not available 
Table 3. Average values of the key model parameters utilized for the process scale-up and results of the sensitivity analysis

\begin{tabular}{|c|c|c|c|c|c|c|c|c|}
\hline Parameter & $\begin{array}{l}K_{e q, P C} \\
(\mathrm{~L} / \mathrm{kg}\end{array}$ & resin) & $\begin{array}{l}k_{L} a \\
(1 / \mathrm{s})\end{array}$ & & $\begin{array}{l}\alpha_{L, \text { resin }} \\
(\mathrm{m})\end{array}$ & & $\begin{array}{l}\mathcal{E}_{\text {resin }} \\
(-)\end{array}$ & \\
\hline Average optimal value $^{a}$ & 131 & & 0.003 & & 0.034 & & 0.86 & \\
\hline $95 \%$ confidence interval & 21 & & 0.0003 & & 0.021 & & 0.03 & \\
\hline Minimum \& maximum value ${ }^{b}$ & 110 & 152 & 0.0027 & 0.0033 & 0.013 & 0.055 & 0.83 & 0.89 \\
\hline$\Delta \eta_{\text {resin }}{ }^{\mathrm{c}}$ & $0.2 \%$ & $-0.2 \%$ & $-5.0 \%$ & $4.2 \%$ & $3.9 \%$ & $-3.5 \%$ & $-1.8 \%$ & $1.9 \%$ \\
\hline
\end{tabular}

${ }^{\mathrm{a}}$ Average of the values relative to tests T2 and T4-T6.

${ }^{\mathrm{b}}$ Obtained for each parameter as (average value - 95\% confidence interval) and (average value $+95 \%$ confidence interval).

${ }^{\mathrm{c}}$ Relative variation of $\eta_{\text {resin }}$ obtained by running a simulation of the adsorption step with the minimum or maximum value of one parameter, and with the average values for the other parameters. 
Table 4. Comparison of LCA results obtained by applying five different methods: total score per season and per $\mathrm{m}^{3}$ OMw and relative contribution of the main lifecycle stages to the total score

\begin{tabular}{|c|c|c|c|c|c|}
\hline Method & \begin{tabular}{|l|} 
Total impac \\
per season
\end{tabular} & $\begin{array}{l}\text { Total impact per } \\
\mathrm{m}^{3}\end{array}$ & $\begin{array}{l}\text { Infra- } \\
\text { structure }\end{array}$ & Operation & $\begin{array}{l}\text { End of life } \\
(\mathrm{EOL})\end{array}$ \\
\hline ILCD Midpoint + v1.10 & $46 \mathrm{Pt}$ & $4.6 \mathrm{mPt} / \mathrm{m}^{3}$ & $20 \%$ & $22 \%$ & $58 \%$ \\
\hline Ecological Scarcity 2013 & $87 \mathrm{MPt}$ & $8.7 \mathrm{kPt} / \mathrm{m}^{3}$ & $6 \%$ & $40 \%$ & $54 \%$ \\
\hline $\begin{array}{l}\text { Cumulative Energy Demand } \\
\text { V1.09 }\end{array}$ & $302 \mathrm{MWh}$ & $109 \mathrm{MJ} / \mathrm{m}^{3}$ & $4 \%$ & $85 \%$ & $11 \%$ \\
\hline IPCC 2013 GWP 20a & 88 tons $\mathrm{CO}_{2, \mathrm{eq}}$ & $8.8 \mathrm{~kg} \mathrm{CO}_{2, \mathrm{eq}} / \mathrm{m}^{3}$ & $3 \%$ & $61 \%$ & $36 \%$ \\
\hline Impact 2002+: Human health & $0.6 \mathrm{Pt}$ & $0.06 \mathrm{mPt} / \mathrm{m}^{3}$ & $13 \%$ & $41 \%$ & $46 \%$ \\
\hline Impact 2002+: Ecosystem quality & $0.8 \mathrm{Pt}$ & $0.08 \mathrm{mPt} / \mathrm{m}^{3}$ & $2 \%$ & $2 \%$ & $96 \%$ \\
\hline Impact 2002+: Resources & $0.7 \mathrm{Pt}$ & $0.07 \mathrm{mPt} / \mathrm{m}^{3}$ & $4 \%$ & $86 \%$ & $10 \%$ \\
\hline
\end{tabular}


Table 5. Relative contribution of the single CAPEX and OPEX elements to the total cost of the PC adsorption / desorption process, equal to $531950 €$ relatively to the 20 -year period taken in consideration

\begin{tabular}{lll}
\hline & CAPEX or OPEX element & $\begin{array}{l}\text { \% contribution to the } \\
\text { total cost }\end{array}$ \\
\hline CAPEX & Adsorption / desorption column, storage tanks, pumps & $16.4 \%$ \\
& Rotary dryer with gas boiler for desorption solvent evaporation & $15.8 \%$ \\
& Condenser for ethanol recovery, with cooling tower & $11.3 \%$ \\
& Microfiltration unit & $4.5 \%$ \\
\hline OPEX & Resin XAD16N periodic disposal and re-integration & $25.1 \%$ \\
& Labour costs (plant control + periodic maintenance) & $13.3 \%$ \\
& Desorption solvent periodic re-integration (ethanol + HCl) & $4.3 \%$ \\
Electricity for pumping & $4.2 \%$ \\
Solid waste treatment (solids from microfiltration) & $1.9 \%$ \\
& Heat for ethanol evaporation & $1.6 \%$ \\
Water periodic re-integration & $1.5 \%$ \\
\hline
\end{tabular}



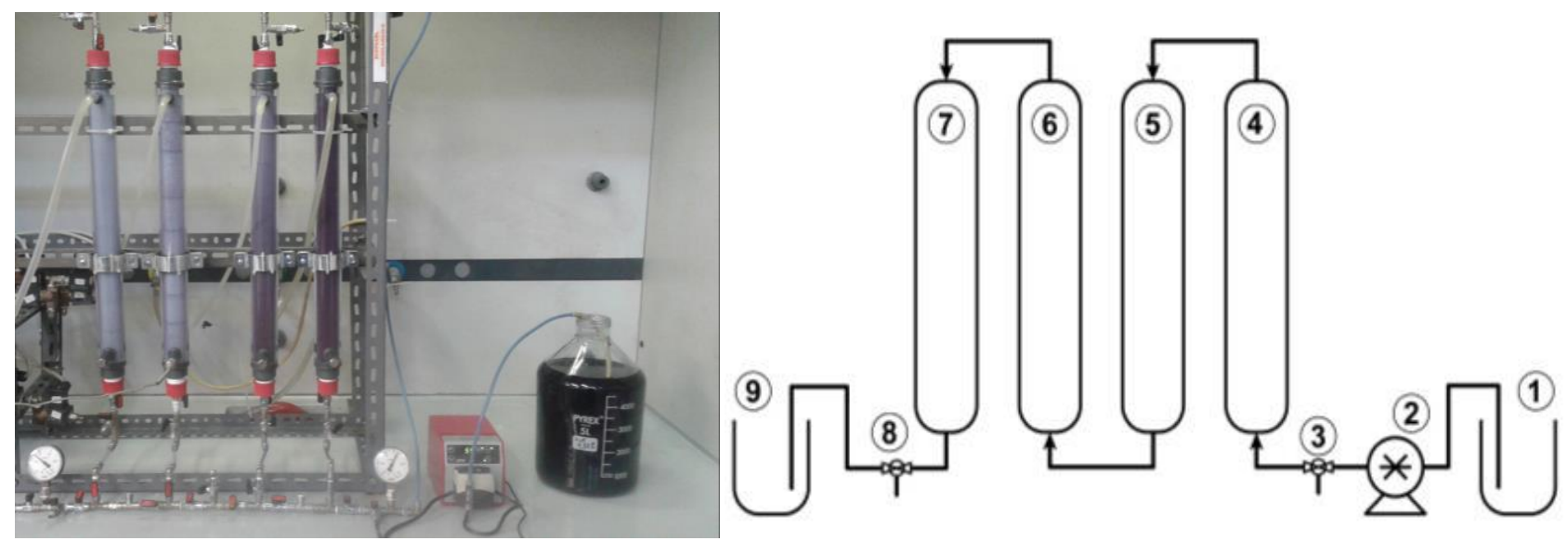

Figure 1. Flow sheet and picture of the adsorption / desorption plant. 1, tank for raw OMW or desorption solvent; 2, centrifugal pump; 3, sampling point for inlet OMW or desorption solvent; 4-7, adsorption / desorption columns; 8, sampling point for effluent of the adsorption / desorption process; 9, tank for dephenolized OMW or PC-rich desorption solvent.

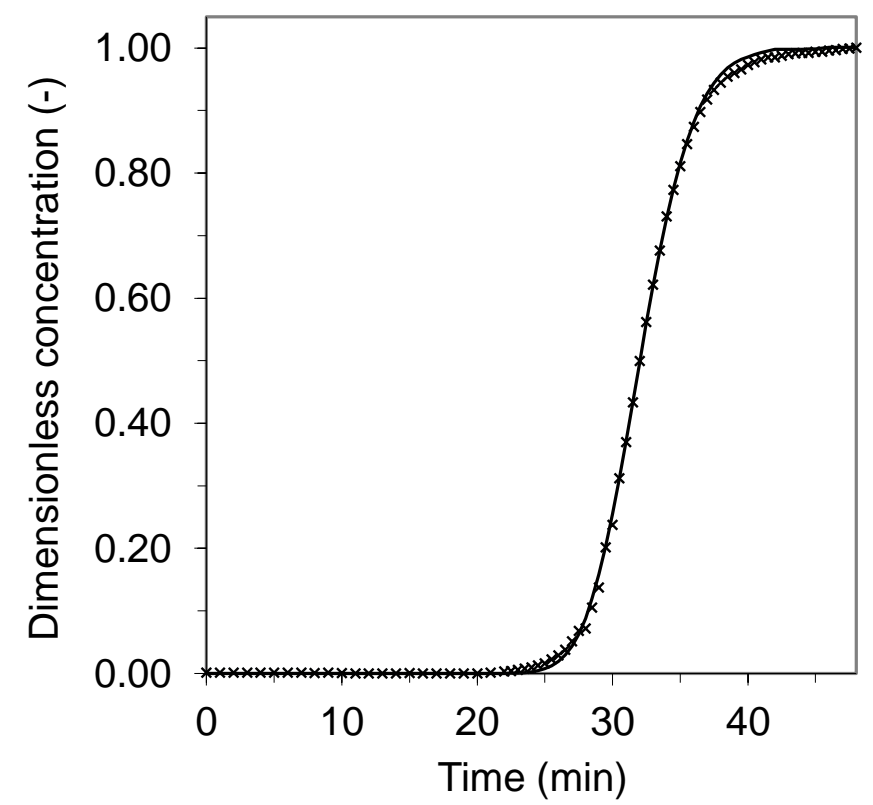

Figure 2. Experimental and best-fitting tracer $(\mathrm{NaCl})$ concentrations at the column outlet obtained in the frontal analysis test conducted before adsorption test $\mathrm{T} 1$. The simulation was performed according to Equation (1), with the retardation factor $\delta_{i}$ set to 1 due to the lack of $\mathrm{NaCl}$ adsorption on XAD16N. 


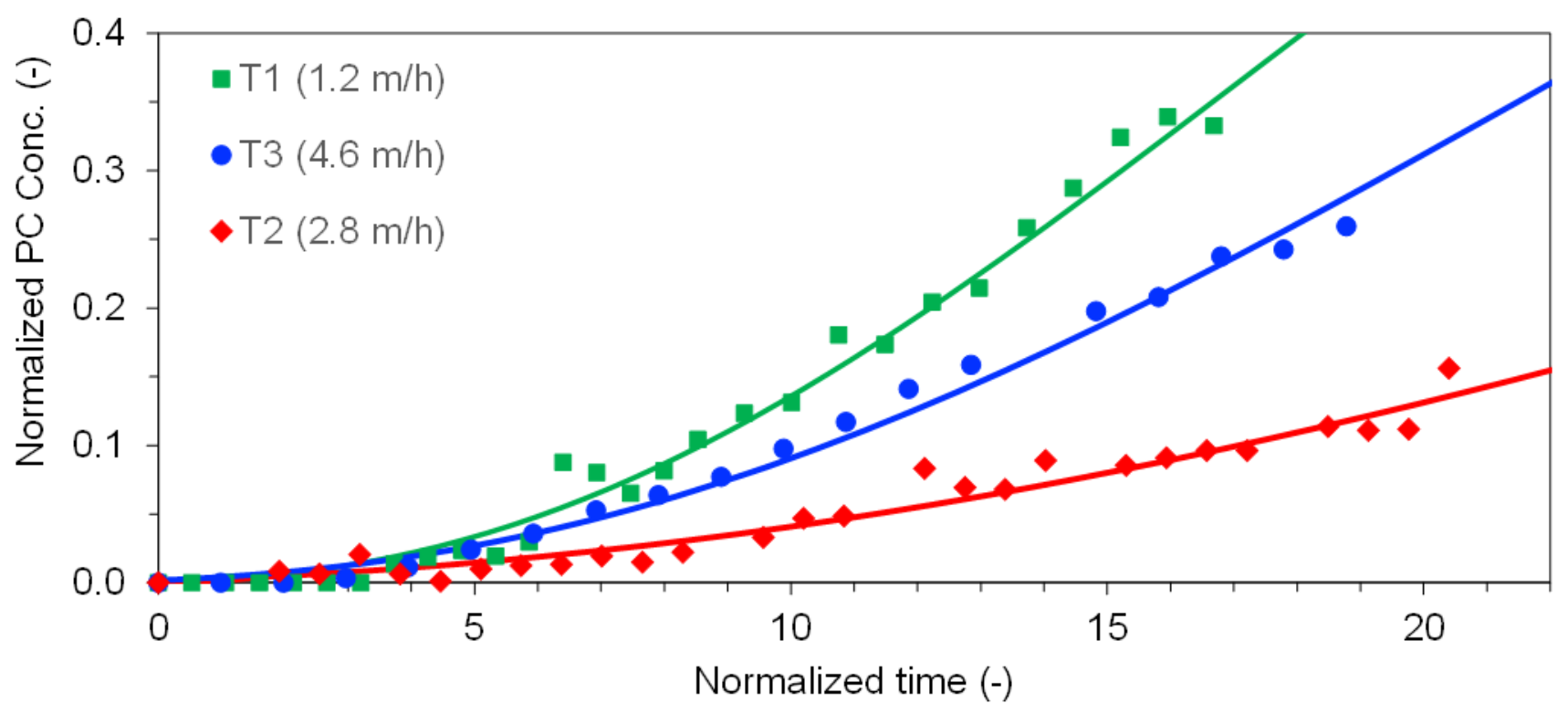

Figure 3. Experimental and best-fitting profiles of PC normalized concentrations at the column outlet versus normalized time (defined as (actual time) / (resin HRT)) for tests T1-T3. The simulations were performed according to Equations (2) and (3). The best-fitting values of the model parameters are reported in Table 2. 


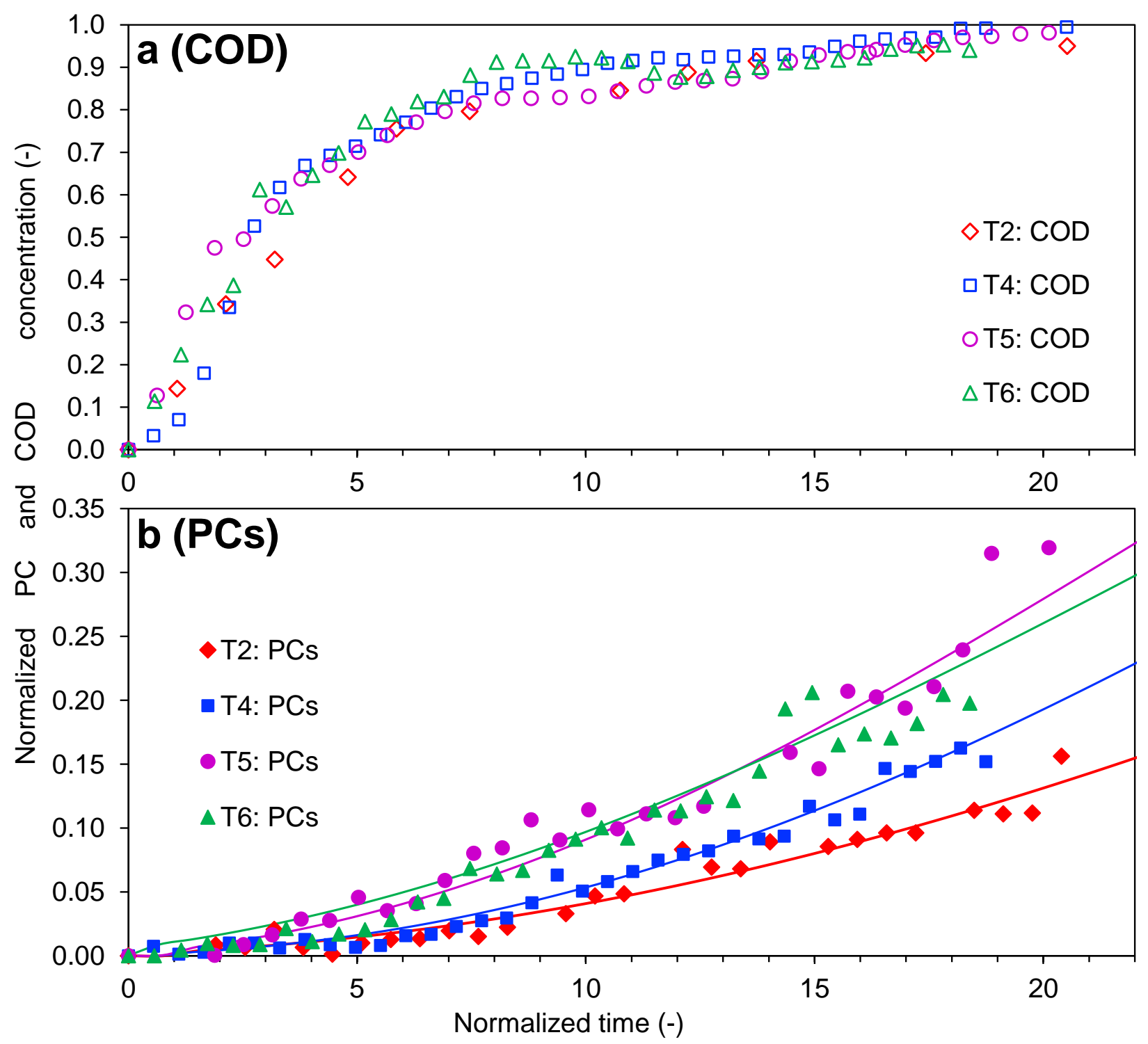

Figure 4. COD (a) and PC (b) normalized concentrations at the column outlet versus normalized time (defined as (actual time) / (resin HRT)) for tests T2, T4, T5, T6, corresponding to the optimal operational condition. Best-fitting simulations of the normalized PC concentrations, performed according to Equations (2) and (3). The best-fitting values of the model parameters are reported in Table 2. 


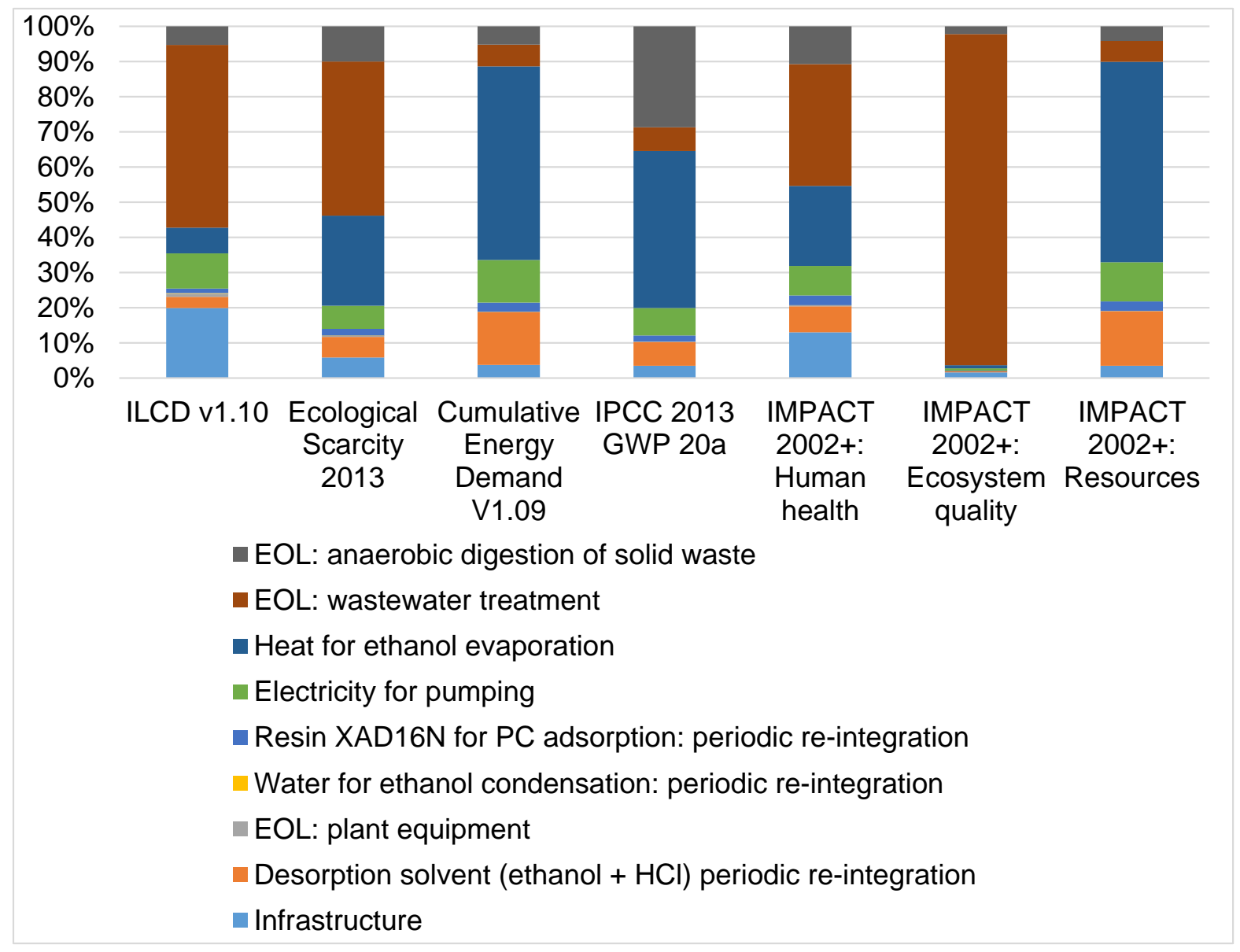

Figure 5. Comparison of the LCA results obtained with the 5 selected methods: relative contribution of the main lifecycle stages to the total score. The impacts associated to plant operation were subdivided into the main components: periodic re-integration of ethanol, $\mathrm{HCl}$, water and resin XAD16N, electricity for pumping, heat for solvent evaporation.

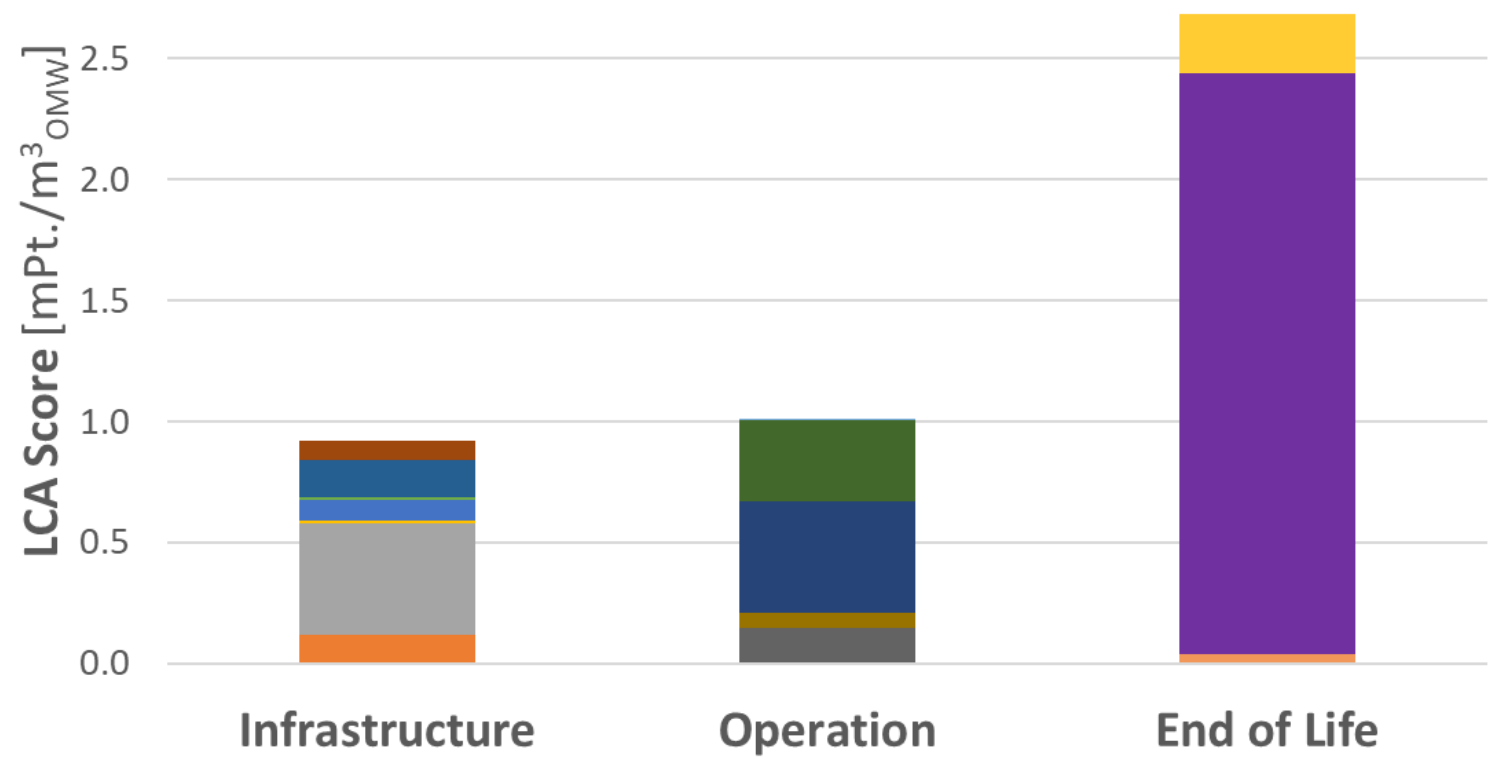

Figure 6. Environmental burden of the different life cycle stages of the proposed process for PC recovery from OMW, according to the ILCD 2011 Midpoint+ method v1.10. 


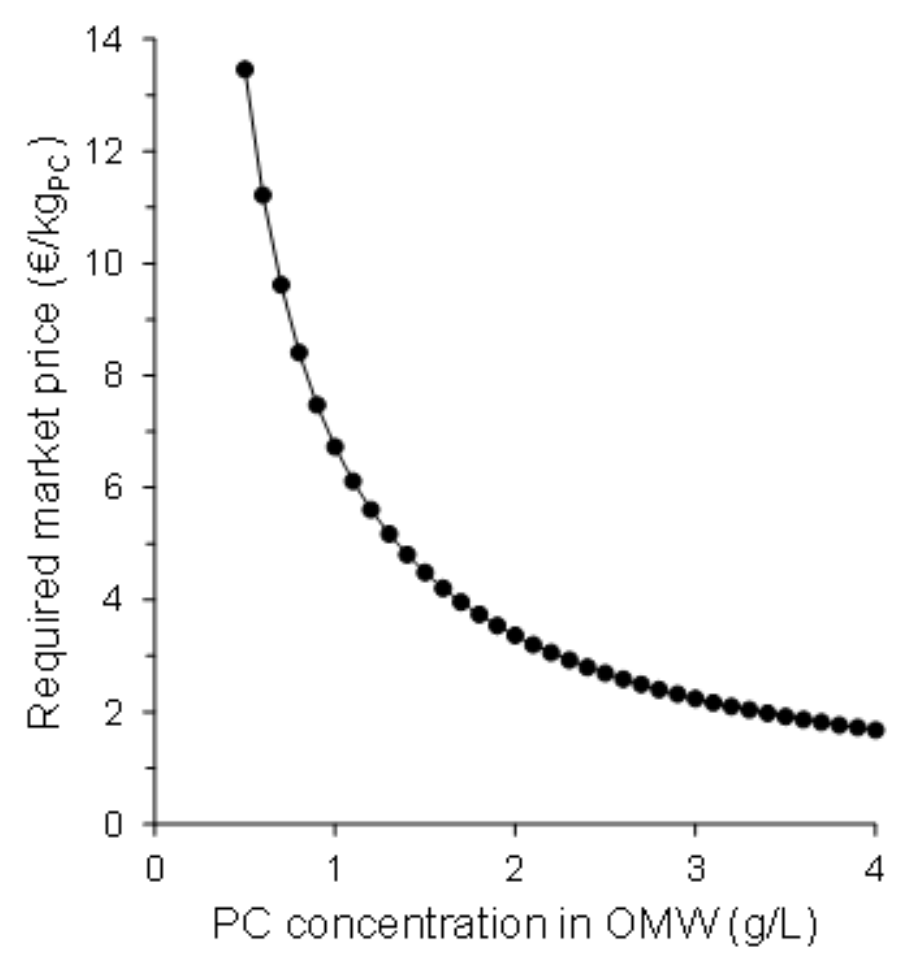

Figure 7. PC market price required to generate a positive business case according to the WACC method, as a function of the PC content in OMW. 


\section{Continuous flow adsorption of phenolic compounds from olive mill wastewater with resin XAD16N: life cycle assessment, cost-benefit analysis and process optimization}

Dario Frascari, Aurora Esther Molina Bacca, Tjerk Wardenaar, Emmanuel Oertlé, Davide Pinelli

\section{SUPPORTING INFORMATION}

\section{Table S1}

Procedure for the evaluation of the performance indicators obtained from the breakthrough tests.

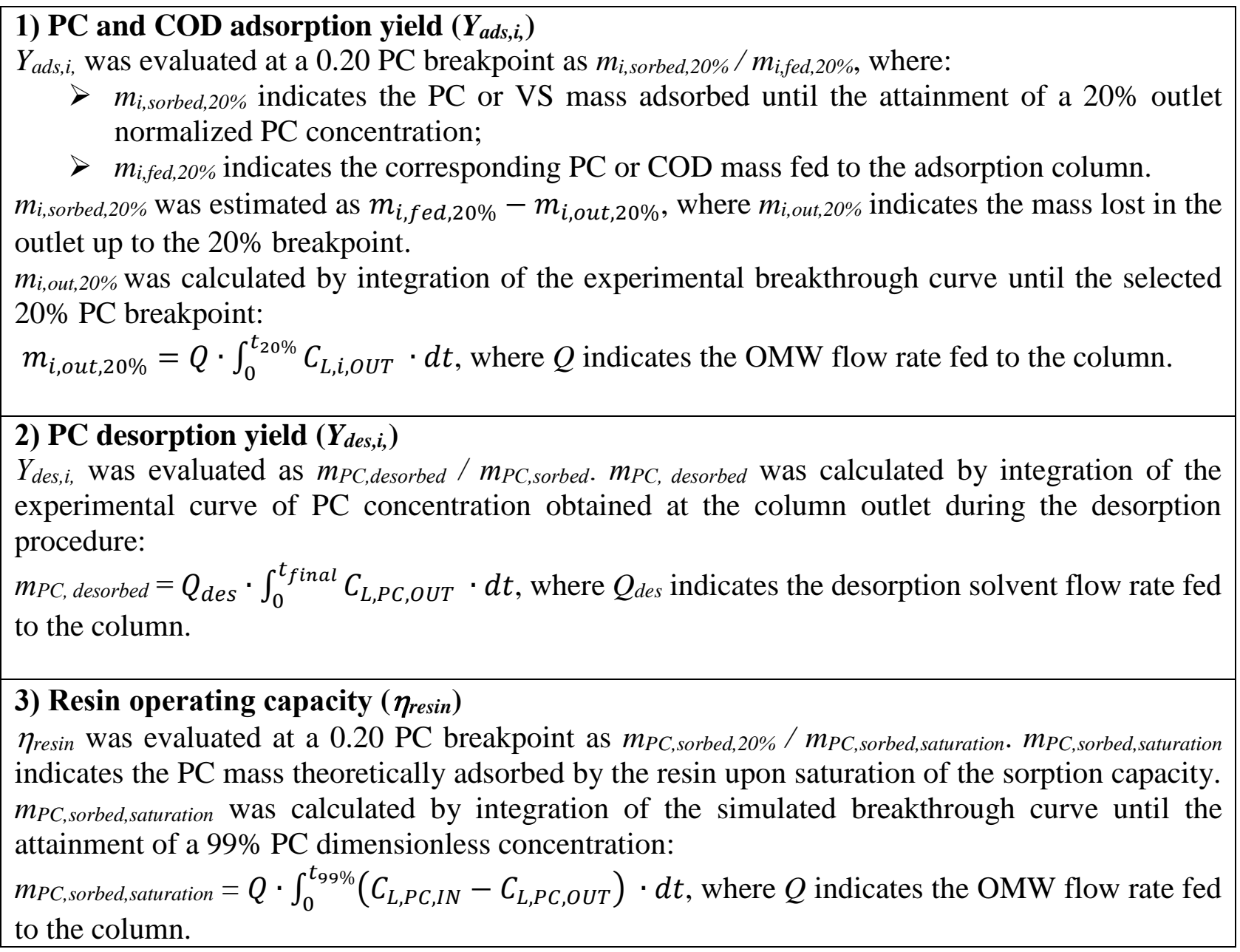




\section{Table S2}

Procedure for the sensitivity analysis aimed at evaluating the sensitivity of the model to variations of the key parameters $\left(K_{e q, P C}, k_{L} a, \alpha_{L, \text { resin }}, \mathcal{E}_{\text {resin }}\right)$ and assessing the uncertainty in the estimate of the resin operating capacity.

\begin{tabular}{|c|c|}
\hline Step & ion \\
\hline $\mathrm{a}$ & $\begin{array}{l}\text { As the intermediate conditions of superficial velocity and HRT resulted in the best process } \\
\text { performances in terms of resin operating capacity and sorbed product purity, the average } \\
\text { values of the model parameters obtained in the } 4 \text { repeated tests (T2 and T4-T6) conducted } \\
\text { under these intermediate conditions were selected as the optimal ones for the process } \\
\text { scale-up and for the sensitivity analysis: superficial velocity }=2.78 \pm 0.25 \mathrm{~m} / \mathrm{h} \text {; HRT in the } \\
\text { resin }=0.56 \pm 0.04 \mathrm{~h} ; K_{\text {eq,PC }}=131 \pm 21 \mathrm{~L} / \mathrm{kg}_{\text {dry resin }} ; k_{L} a=0.0030 \pm 0.00031 / \mathrm{s} ; \alpha_{L, \text { resin }}= \\
0.034 \pm 0.021 \mathrm{~m} ; \varepsilon_{\text {resin }}=0.86 \pm 0.03 \text {. }\end{array}$ \\
\hline$b$ & $\begin{array}{l}\text { The resin operating capacity } \eta_{\text {resin }}-\text { selected as key performance parameter - resulting } \\
\text { from a process simulation conducted with these average parameter values and with the } \\
\text { same resin bed height of the experimental plant }(1.82 \mathrm{~m}) \text { was evaluated }(0.456) \text {. }\end{array}$ \\
\hline $\mathrm{c}$ & $\begin{array}{l}\text { Starting from the "baseline condition" simulated in step b), further simulations were } \\
\text { conducted in which one model parameter was taken equal to the maximum or minimum } \\
\text { value allowed by the } 95 \% \text { confidence interval reported in step a), whereas the other } \\
\text { parameters were maintained equal to the average value reported in step b); these } \\
\text { parameter variations were extended to } K_{e q, P C}, k_{L} a, \alpha_{L, \text { resin }} \text { and } \varepsilon_{\text {resin }} \text {, but not to superficial } \\
\text { velocity and HRT, under the assumption that in a full-scale process the OMW flow rate, } \\
\text { and therefore the velocity and - given the resin bed height and porosity - the HRT, is } \\
\text { controlled in a very precise way; this approach therefore resulted in } 8 \text { additional } \\
\text { simulations. }\end{array}$ \\
\hline$d$ & $\begin{array}{l}\text { For each simulation included in step c), the relative variation in resin operating capacity in } \\
\text { comparison with the baseline value calculated in step b) was determined. }\end{array}$ \\
\hline
\end{tabular}




\section{Table S3}

Design values and performance parameters of the full-scale plant of OMW filtration, PC adsorption / desorption and ethanol recovery.

\begin{tabular}{|l|r|l|}
\hline Parameter & Value & Unit \\
\hline Total OMW treated & 10000 & $\mathrm{~m}^{3}$ \\
\hline OMW flow rate at the adsorption step & 4.17 & $\mathrm{~m}^{3} / \mathrm{h}$ \\
\hline Ethanol flow rate at the desorption step & 2.08 & $\mathrm{~m}^{3} / \mathrm{h}$ \\
\hline Duration of the adsorption / desorption cycle & 14.7 & $\mathrm{~h}$ \\
\hline Column diameter & 1.38 & $\mathrm{~m}$ \\
\hline Resin bed height & 1.82 & $\mathrm{~m}$ \\
\hline OMW superficial velocity in the adsorption step & 2.78 & $\mathrm{~m} / \mathrm{h}$ \\
\hline$H R T$ of the adsorption step & 0.56 & $\mathrm{~h}$ \\
\hline Bed volumes / hour of the adsorption step & 1.53 & $\mathrm{BV} / \mathrm{h}$ \\
\hline Adsorption yield & 0.922 & - \\
\hline Desorption yield & 0.704 & - \\
\hline Process yield & 0.650 & - \\
\hline Resin operating capacity & 0.456 & - \\
\hline $\begin{array}{l}\text { Number of adsorption / desorption cycles performed with the same } \\
\text { resin load }\end{array}$ & 500 & - \\
\hline
\end{tabular}




\section{Table S4}

Inventory for the LCA and CBA of the process.

\begin{tabular}{|c|c|c|}
\hline & Amount & Unit \\
\hline \multicolumn{3}{|l|}{ Infrastructure } \\
\hline Microfiltration unit & 1 & unit \\
\hline $\begin{array}{l}\text { Adsorption / desorption column (diameter } 1.38 \mathrm{~m} \text {, resin bed height } \\
1.82 \mathrm{~m} \text { ) }\end{array}$ & 1 & unit \\
\hline Desorption solvent evaporation / recovery unit (rotary dryer) & 1 & unit \\
\hline Desorption solvent and OMW storage tanks & 2 & units \\
\hline Gas Boiler $(85 \mathrm{~kW})$ & 1 & unit \\
\hline Ethanol recovery condenser $\left(3.4 \mathrm{~m}^{2}\right)$ & 1 & unit \\
\hline Cooling Tower & 1 & unit \\
\hline Pumps $\left(2-4.2 \mathrm{~m}^{3} / \mathrm{h}\right)$ & 4 & pumps \\
\hline \multicolumn{3}{|l|}{ Operation } \\
\hline Ethanol periodic re-integration & 4.5 & $\mathrm{~m}^{3} / \mathrm{season}$ \\
\hline $\mathrm{HCl}$ periodic re-integration & 27 & $\mathrm{~kg} / \mathrm{season}$ \\
\hline Resin XAD16N periodic disposal and re-integration & 350 & $\mathrm{~kg} / \mathrm{season}$ \\
\hline Water periodic re-integration & 405 & $\mathrm{~m}^{3} / \mathrm{season}$ \\
\hline Electricity for pumping & 12000 & $\mathrm{kWh} /$ season \\
\hline Heat for ethanol evaporation & 990500 & MJ/season \\
\hline PC mass produced & $3.25-26^{\mathrm{a}}$ & tPC/season \\
\hline \multicolumn{3}{|l|}{ End of Life (EOL) } \\
\hline Wastewater produced & 10000 & $\mathrm{~m}^{3} / \mathrm{season}$ \\
\hline Solid waste sent to anaerobic digestion & 30000 & $\mathrm{~kg} / \mathrm{season}$ \\
\hline Infrastructure & 12 & units \\
\hline
\end{tabular}

${ }^{a}$ In order to develop a CBA applicable to different OMW types, and not only to the specific OMW object of this work, the PC concentration in OMW was assumed to vary over the $0.5-4 \mathrm{~g} / \mathrm{L}$ range. 
Table S5. LCA of the PC recovery process: impact of each life cycle stage and component of the process on the different environmental compartments and aspects taken into consideration in the ILCD 2011 Midpoint+ V1.10 method. For each environmental compartments and aspect, the table reports the total impact of the process, and the \% relative impact of each life cycle stage and component.

\begin{tabular}{|c|c|c|c|c|c|c|c|c|c|c|c|}
\hline \multirow[t]{2}{*}{ Impact category } & \multirow[t]{2}{*}{ Unit } & \multirow{2}{*}{$\begin{array}{l}\text { Total LCA } \\
\text { score }\end{array}$} & \multirow{2}{*}{$\begin{array}{l}\text { Infra- } \\
\text { structure }\end{array}$} & \multicolumn{5}{|c|}{ Operation } & \multicolumn{3}{|c|}{ End of life } \\
\hline & & & & $\begin{array}{c}\text { Desorption } \\
\text { solvent } \\
(\text { ethanol + } \\
\mathrm{HCl})^{\mathrm{a}}\end{array}$ & Water $^{\mathrm{a}}$ & $\begin{array}{c}\text { Resin } \\
\text { XAD16N }^{a}\end{array}$ & $\begin{array}{l}\text { Electricity } \\
\text { for pumps }\end{array}$ & $\begin{array}{c}\text { Heat for ethanol } \\
\text { evaporation }\end{array}$ & $\begin{array}{c}\text { EOL - } \\
\text { Diverse }^{b}\end{array}$ & $\begin{array}{c}\text { Wastewater } \\
\text { treatment }\end{array}$ & $\begin{array}{l}\text { Solid waste } \\
\text { anaerobic } \\
\text { digestion }\end{array}$ \\
\hline Climate change & $\mathrm{kg} \mathrm{CO}_{2} \mathrm{eq}$ & $6.42 \cdot 10^{0}$ & $3.9 \%$ & $6.8 \%$ & $<0.1 \%$ & $1.7 \%$ & $9.4 \%$ & $51.7 \%$ & $0.2 \%$ & $10.8 \%$ & $15.6 \%$ \\
\hline Ozone depletion & kg CFC-11 eq & $6.67 \cdot 10^{-7}$ & $1.8 \%$ & $1.8 \%$ & $<0.1 \%$ & $0.7 \%$ & $9.0 \%$ & $78.4 \%$ & $0.1 \%$ & $5.5 \%$ & $2.7 \%$ \\
\hline \begin{tabular}{|l|} 
Human toxicity, non- \\
cancer effects
\end{tabular} & CTUh & $3.66 \cdot 10^{-6}$ & $5.3 \%$ & $1.6 \%$ & $<0.1 \%$ & $0.7 \%$ & $4.0 \%$ & $2.8 \%$ & $0.4 \%$ & $82.0 \%$ & $3.3 \%$ \\
\hline $\begin{array}{l}\text { Human toxicity, } \\
\text { cancer effects }\end{array}$ & CTUh & $4.05 \cdot 10^{-7}$ & $31.8 \%$ & $3.3 \%$ & $<0.1 \%$ & $1.3 \%$ & $9.4 \%$ & $7.3 \%$ & $0.4 \%$ & $41.6 \%$ & $4.8 \%$ \\
\hline Particulate matter & kg PM2.5 eq & $2.22 \cdot 10^{-3}$ & $16.0 \%$ & $10.3 \%$ & $<0.1 \%$ & $3.7 \%$ & $9.9 \%$ & $18.5 \%$ & $0.3 \%$ & $20.2 \%$ & $21.0 \%$ \\
\hline Ionizing radiation $\mathrm{HH}$ & $\mathrm{kBq} \mathrm{U} 235 \mathrm{eq}$ & $4.64 \cdot 10^{-1}$ & $3.4 \%$ & $1.6 \%$ & $<0.1 \%$ & $1.1 \%$ & $58.4 \%$ & $17.5 \%$ & $0.1 \%$ & $14.0 \%$ & $4.0 \%$ \\
\hline $\begin{array}{l}\begin{array}{l}\text { Ionizing radiation } \mathrm{E} \\
\text { (interim) }\end{array} \\
\end{array}$ & CTUe & $1.42 \cdot 10^{-6}$ & $4.2 \%$ & $2.0 \%$ & $<0.1 \%$ & $1.3 \%$ & $48.8 \%$ & $24.9 \%$ & $0.1 \%$ & $13.7 \%$ & $5.0 \%$ \\
\hline $\begin{array}{l}\text { Photochemical ozone } \\
\text { formation }\end{array}$ & $\begin{array}{c}\text { kg NMVOC } \\
\text { eq }\end{array}$ & $1.23 \cdot 10^{-2}$ & $7.1 \%$ & $17.8 \%$ & $<0.1 \%$ & $4.0 \%$ & $9.6 \%$ & $33.8 \%$ & $0.3 \%$ & $18.2 \%$ & $9.2 \%$ \\
\hline Acidification & $\mathrm{mol} \mathrm{H}^{+} \mathrm{eq}$ & $2.40 \cdot 10^{-2}$ & $7.1 \%$ & $8.1 \%$ & $<0.1 \%$ & $2.4 \%$ & $13.7 \%$ & $24.0 \%$ & $0.2 \%$ & $24.3 \%$ & $20.2 \%$ \\
\hline $\begin{array}{l}\text { Terrestrial } \\
\text { eutrophication }\end{array}$ & mol $\mathrm{N}$ eq & $5.21 \cdot 10^{-2}$ & $5.2 \%$ & $6.8 \%$ & $<0.1 \%$ & $1.6 \%$ & $8.1 \%$ & $22.7 \%$ & $0.3 \%$ & $30.1 \%$ & $25.2 \%$ \\
\hline $\begin{array}{l}\text { Freshwater } \\
\text { eutrophication }\end{array}$ & $\mathrm{kg} P$ eq & $2.36 \cdot 10^{-3}$ & $5.8 \%$ & $7.6 \%$ & $<0.1 \%$ & $1.5 \%$ & $21.5 \%$ & $7.8 \%$ & $0.2 \%$ & $48.6 \%$ & $7.0 \%$ \\
\hline $\begin{array}{l}\text { Marine } \\
\text { eutrophication }\end{array}$ & $\mathrm{kg} \mathrm{N} \mathrm{eq}$ & $2.39 \cdot 10^{-2}$ & $1.1 \%$ & $1.4 \%$ & $<0.1 \%$ & $0.3 \%$ & $2.0 \%$ & $4.7 \%$ & $0.1 \%$ & $87.8 \%$ & $2.6 \%$ \\
\hline $\begin{array}{l}\text { Freshwater } \\
\text { ecotoxicity }\end{array}$ & CTUe & $3.30 \cdot 10^{1}$ & $18.7 \%$ & $4.7 \%$ & $<0.1 \%$ & $2.3 \%$ & $15.0 \%$ & $8.8 \%$ & $4.0 \%$ & $38.6 \%$ & $8.0 \%$ \\
\hline Land use & $\mathrm{kg} \mathrm{C}$ deficit & $1.29 \cdot 10^{1}$ & $3.4 \%$ & $1.7 \%$ & $<0.1 \%$ & $0.6 \%$ & $3.6 \%$ & $17.1 \%$ & $0.1 \%$ & $34.1 \%$ & $39.4 \%$ \\
\hline $\begin{array}{l}\text { Water resource } \\
\text { depletion }^{c}\end{array}$ & $\mathrm{~m}^{3}$ water eq & $-1.38 \cdot 10^{1}$ & $0.4 \%$ & $<0.1 \%$ & $-4.7 \%$ & $-0.1 \%$ & $-2.7 \%$ & $2.1 \%$ & $<0.1 \%$ & $105.0 \%$ & $<0.1 \%$ \\
\hline $\begin{array}{l}\text { Mineral, fossil \& ren. } \\
\text { resource depletion }\end{array}$ & $\mathrm{kg} \mathrm{Sb}$ eq & $1.05 \cdot 10^{-4}$ & $41.3 \%$ & $11.9 \%$ & $<0.1 \%$ & $7.7 \%$ & $4.1 \%$ & $4.9 \%$ & $2.5 \%$ & $20.8 \%$ & $6.9 \%$ \\
\hline
\end{tabular}

${ }^{a}$ Periodic re-integration. ${ }^{\mathrm{b}}$ Infrastructure disposal + spent resin incineration. ${ }^{\mathrm{c}}$ The negative LCA score in terms of water resource depletion, indicating a positive environmental

impact, is due to the wastewater treatment process, which increases the availability of high-quality water. 
Table S6. LCA of the PC recovery process: impact of each life cycle stage and component of the process on the different environmental compartments and aspects taken into consideration in the Ecological Scarcity 2013 method. For each environmental compartments and aspect, the table reports the total impact of the process, and the \% relative impact of each life cycle stage and component.

\begin{tabular}{|c|c|c|c|c|c|c|c|c|c|c|}
\hline \multirow{2}{*}{ Impact category } & \multirow{2}{*}{$\begin{array}{l}\text { Total LCA score } \\
(\mathrm{kPt})\end{array}$} & \multirow{2}{*}{$\begin{array}{c}\text { Infra- } \\
\text { structure }\end{array}$} & \multicolumn{5}{|c|}{ Operation } & \multicolumn{3}{|c|}{ End of life } \\
\hline & & & $\begin{array}{c}\text { Desorption } \\
\text { solvent (ethanol } \\
+\mathrm{HCl})^{\mathrm{a}}\end{array}$ & Water $^{\mathrm{a}}$ & \begin{tabular}{|c|} 
Resin \\
XAD16N
\end{tabular} & $\begin{array}{l}\text { Electricity } \\
\text { for pumps }\end{array}$ & $\begin{array}{c}\text { Heat for } \\
\text { ethanol } \\
\text { evaporation }\end{array}$ & $\begin{array}{l}\text { EOL - } \\
\text { Diverse }^{\mathrm{b}}\end{array}$ & $\begin{array}{l}\text { Wastewate } \\
\mathrm{r} \text { treatment }\end{array}$ & $\begin{array}{l}\text { Solid waste } \\
\text { anaerobic } \\
\text { digestion }\end{array}$ \\
\hline Total & $8.67 \cdot 10^{0}$ & $5.9 \%$ & $5.8 \%$ & $0.1 \%$ & $1.8 \%$ & $6.6 \%$ & $25.6 \%$ & $0.3 \%$ & $43.8 \%$ & $10.0 \%$ \\
\hline Water resources ${ }^{\mathrm{c}}$ & $-2.82 \cdot 10^{-1}$ & $0.3 \%$ & $-0.1 \%$ & $-1.9 \%$ & $<0.1 \%$ & $-0.5 \%$ & $0.3 \%$ & $<0.1 \%$ & $101.9 \%$ & $0.1 \%$ \\
\hline Energy resources & $3.60 \cdot 10^{-1}$ & $3.5 \%$ & $15.6 \%$ & $<0.1 \%$ & $2.7 \%$ & $11.4 \%$ & $56.3 \%$ & $0.1 \%$ & $6.0 \%$ & $4.5 \%$ \\
\hline Mineral resources & $1.74 \cdot 10^{-1}$ & $46.9 \%$ & $3.9 \%$ & $<0.1 \%$ & $2.0 \%$ & $1.4 \%$ & $5.9 \%$ & $0.7 \%$ & $36.2 \%$ & $2.9 \%$ \\
\hline Land use & $4.93 \cdot 10^{-2}$ & $3.9 \%$ & $2.1 \%$ & $<0.1 \%$ & $0.7 \%$ & $6.6 \%$ & $2.7 \%$ & $0.1 \%$ & $18.1 \%$ & $65.8 \%$ \\
\hline Global warming & $2.92 \cdot 10^{0}$ & $4.0 \%$ & $6.9 \%$ & $<0.1 \%$ & $1.7 \%$ & $9.4 \%$ & $52.5 \%$ & $0.1 \%$ & $7.9 \%$ & $17.5 \%$ \\
\hline Ozone layer depletion & $4.19 \cdot 10^{-3}$ & $2.5 \%$ & $2.5 \%$ & $<0.1 \%$ & $1.2 \%$ & $11.1 \%$ & $60.7 \%$ & $0.1 \%$ & $8.8 \%$ & $13.1 \%$ \\
\hline Main air pollutants and PM & $1.08 \cdot 10^{0}$ & $14.6 \%$ & $8.5 \%$ & $<0.1 \%$ & $3.2 \%$ & $10.3 \%$ & $24.9 \%$ & $0.3 \%$ & $22.7 \%$ & $15.6 \%$ \\
\hline Carcinogenic substances into air & $2.64 \cdot 10^{-1}$ & $13.5 \%$ & $2.7 \%$ & $<0.1 \%$ & $15.7 \%$ & $4.0 \%$ & $12.3 \%$ & $0.3 \%$ & $36.4 \%$ & $15.2 \%$ \\
\hline Heavy metals into air & $2.11 \cdot 10^{-1}$ & $28.2 \%$ & $8.8 \%$ & $<0.1 \%$ & $3.0 \%$ & $7.7 \%$ & $13.0 \%$ & $1.3 \%$ & $25.7 \%$ & $12.4 \%$ \\
\hline Water pollutants & $2.35 \cdot 10^{0}$ & $0.1 \%$ & $4.8 \%$ & $<0.1 \%$ & $0.3 \%$ & $0.2 \%$ & $1.1 \%$ & $<0.1 \%$ & $91.8 \%$ & $1.8 \%$ \\
\hline POP into water & $1.27 \cdot 10^{-2}$ & $9.1 \%$ & $7.5 \%$ & $<0.1 \%$ & $2.5 \%$ & $8.5 \%$ & $35.4 \%$ & $0.8 \%$ & $22.0 \%$ & $14.2 \%$ \\
\hline Heavy metals into water & $7.28 \cdot 10^{-1}$ & $4.3 \%$ & $0.9 \%$ & $<0.1 \%$ & $0.2 \%$ & $0.9 \%$ & $12.7 \%$ & $0.1 \%$ & $80.2 \%$ & $0.7 \%$ \\
\hline Pesticides into soil & $2.10 \cdot 10^{-2}$ & $0.1 \%$ & $<0.1 \%$ & $<0.1 \%$ & $<0.1 \%$ & $0.3 \%$ & $0.1 \%$ & $<0.1 \%$ & $68.0 \%$ & $31.5 \%$ \\
\hline Heavy metals into soil & $5.60 \cdot 10^{-1}$ & $0.1 \%$ & $0.1 \%$ & $<0.1 \%$ & $<0.1 \%$ & $0.4 \%$ & $0.1 \%$ & $<0.1 \%$ & $98.3 \%$ & $0.9 \%$ \\
\hline Radioactive substances into air & $3.70 \cdot 10^{-8}$ & $3.4 \%$ & $1.6 \%$ & $<0.1 \%$ & $1.1 \%$ & $58.4 \%$ & $17.5 \%$ & $0.1 \%$ & $14.0 \%$ & $4.0 \%$ \\
\hline Radioactive substances into water & $1.77 \cdot 10^{-3}$ & $4.0 \%$ & $1.5 \%$ & $<0.1 \%$ & $1.2 \%$ & $62.3 \%$ & $12.4 \%$ & $0.0 \%$ & $14.3 \%$ & $4.2 \%$ \\
\hline Non radioactive waste to deposit & $5.46 \cdot 10^{-2}$ & $5.8 \%$ & $1.2 \%$ & $<0.1 \%$ & $1.1 \%$ & $0.7 \%$ & $3.4 \%$ & $30.4 \%$ & $56.3 \%$ & $1.1 \%$ \\
\hline Radioactive waste to deposit & $1.60 \cdot 10^{-1}$ & $4.0 \%$ & $1.5 \%$ & $<0.1 \%$ & $1.2 \%$ & $62.3 \%$ & $12.4 \%$ & $0.0 \%$ & $14.3 \%$ & $4.2 \%$ \\
\hline
\end{tabular}

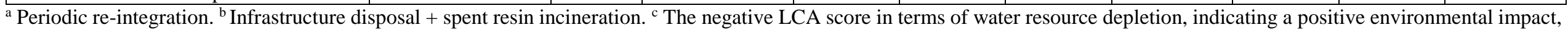
is due to the wastewater treatment process, which increases the availability of high-quality water 